Supporting information

\title{
CoSe@N-Doped Carbon Nanotubes as a Potassium-Ion Battery Anode with High Initial Coulombic Efficiency and Superior Capacity Retention
}

Yanzhen Liu, ," Qiang Deng, ," Youpeng Li, ' Yijuan Li, † Wentao Zhong, ' Junhua Hu,

Xiaohong $\mathrm{Ji},{ }^{\star}$ Chenghao Yang, ${ }^{* \dagger}$ Zhang Lin, ${ }^{\dagger}$ Kevin Huang ${ }^{* \perp}$

Guangzhou Key Laboratory for Surface Chemistry of Energy Materials, New Energy Research Institute, School of Environment and Energy, South China University of Technology, Guangzhou 510006, China

${ }^{s}$ School of Materials Science and Engineering, Zhengzhou University, Zhengzhou 450001, China

${ }^{*}$ School of Materials Science and Engineering, South China University of Technology, Guangzhou 510641, China

${ }^{\perp}$ Department of Mechanical Engineering, University of South Carolina, Columbia, SC 29205, USA

* Corresponding authors: esyangc@scut.edu.cn (C. Yang); huang46@cec.sc.edu (K. Huang)

"Y. Liu and Q. Deng contributed equally to this work.

KEYWORDS: Potassium-ion batteries, anode, Co selenide, surface polymerization, electrochemical performance 


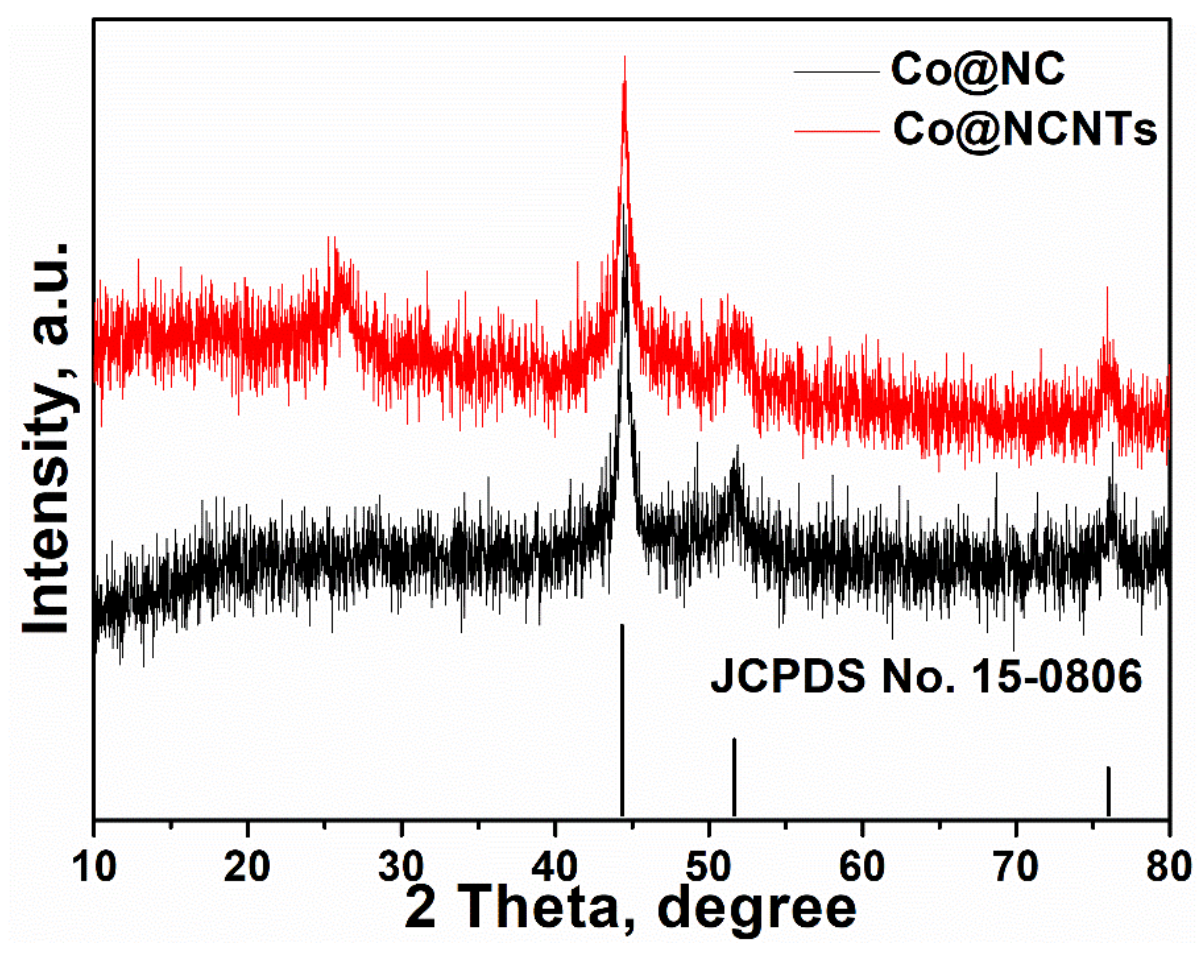

Figure S1.XRD patterns of Co@NC and Co@NCNTs. 

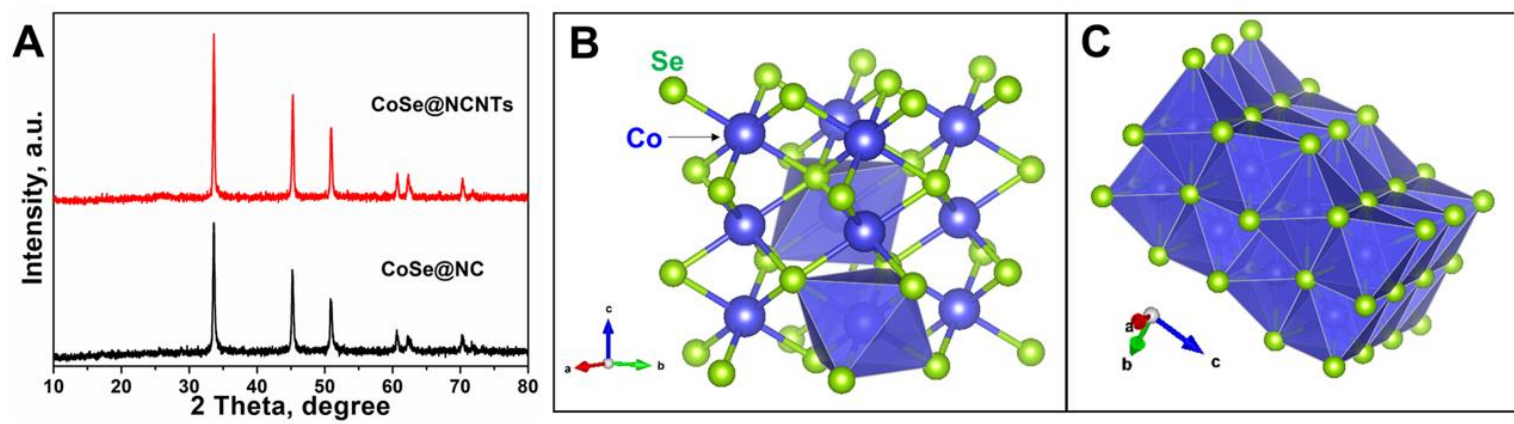

Figure S2. XRD patterns of CoSe@NC and CoSe@NCNTs (A) and the crystal structure of $\operatorname{CoSe}(\mathrm{B}, \mathrm{C})$. 


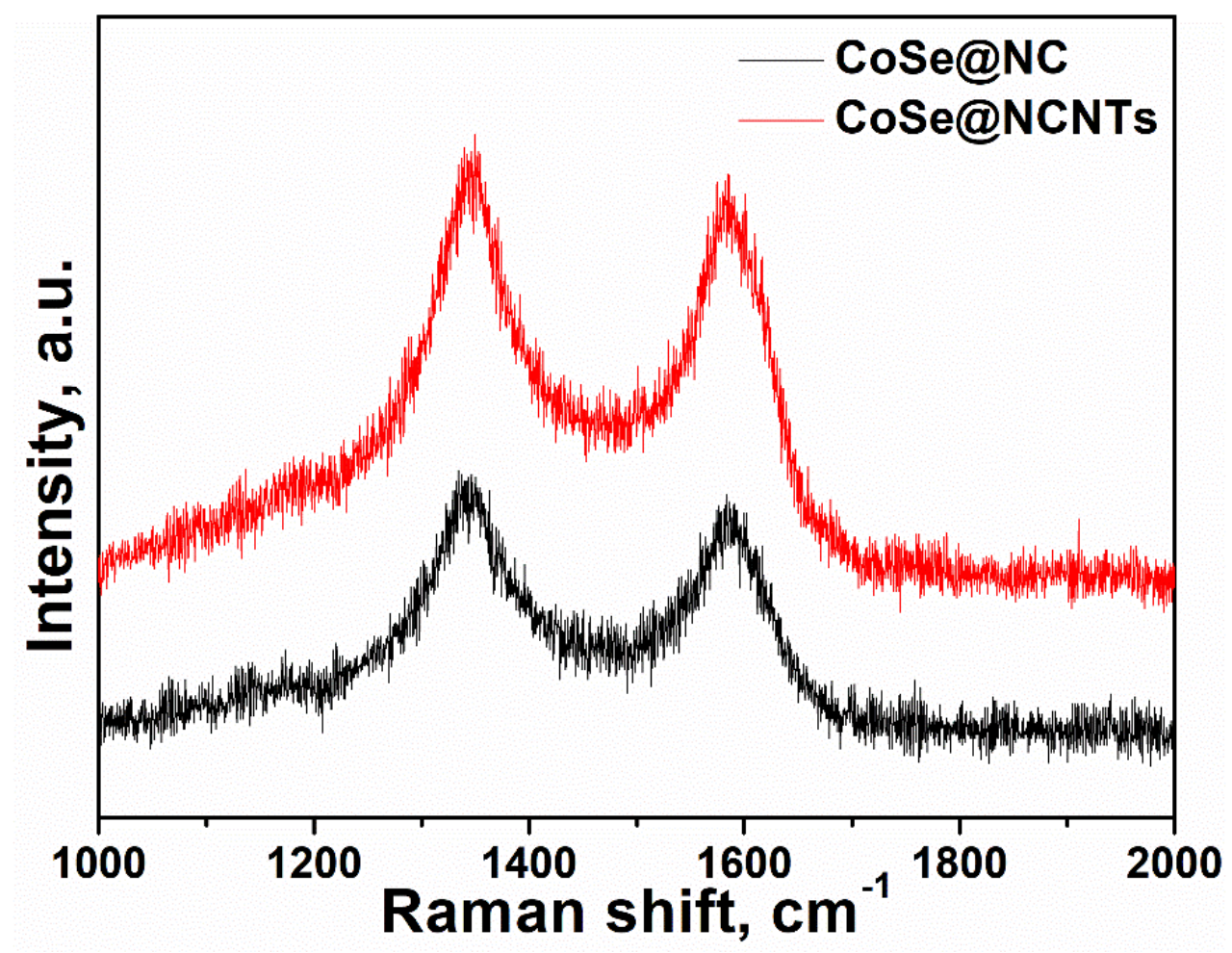

Figure S3. Raman spectra of CoSe@NC and CoSe@NCNTs. 


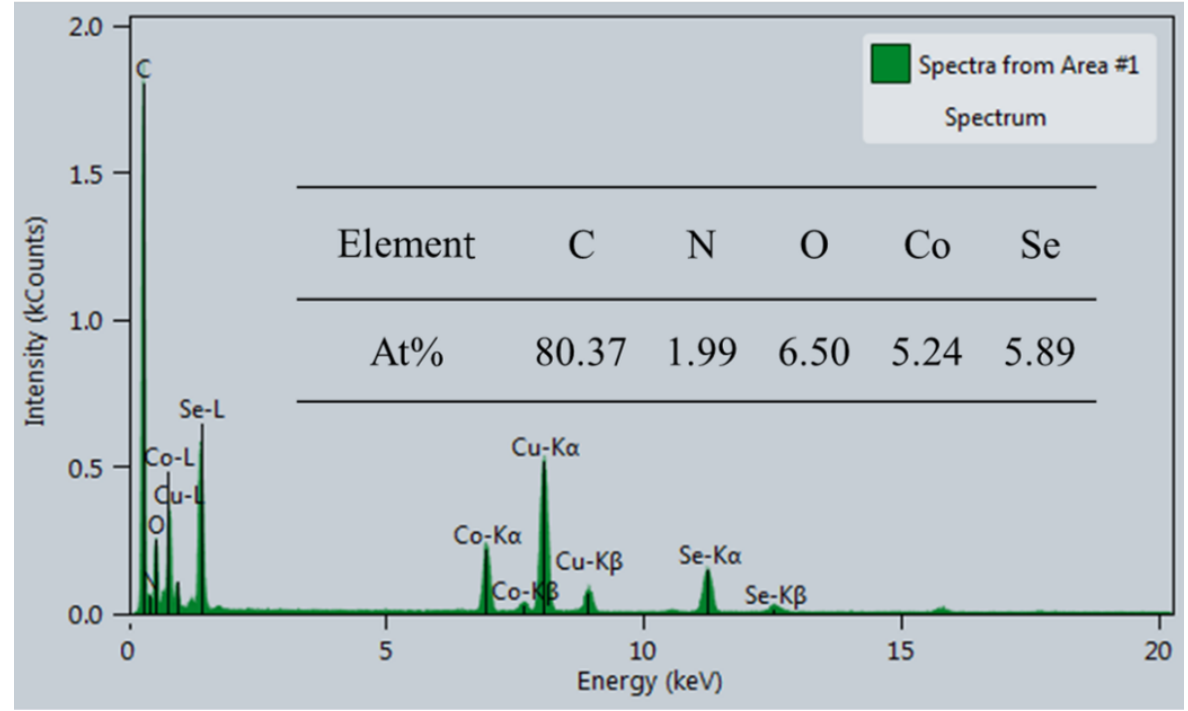

Figure S4. The EDS spectrum and the elemental ratio (insert) of CoSe@NCNTs. 

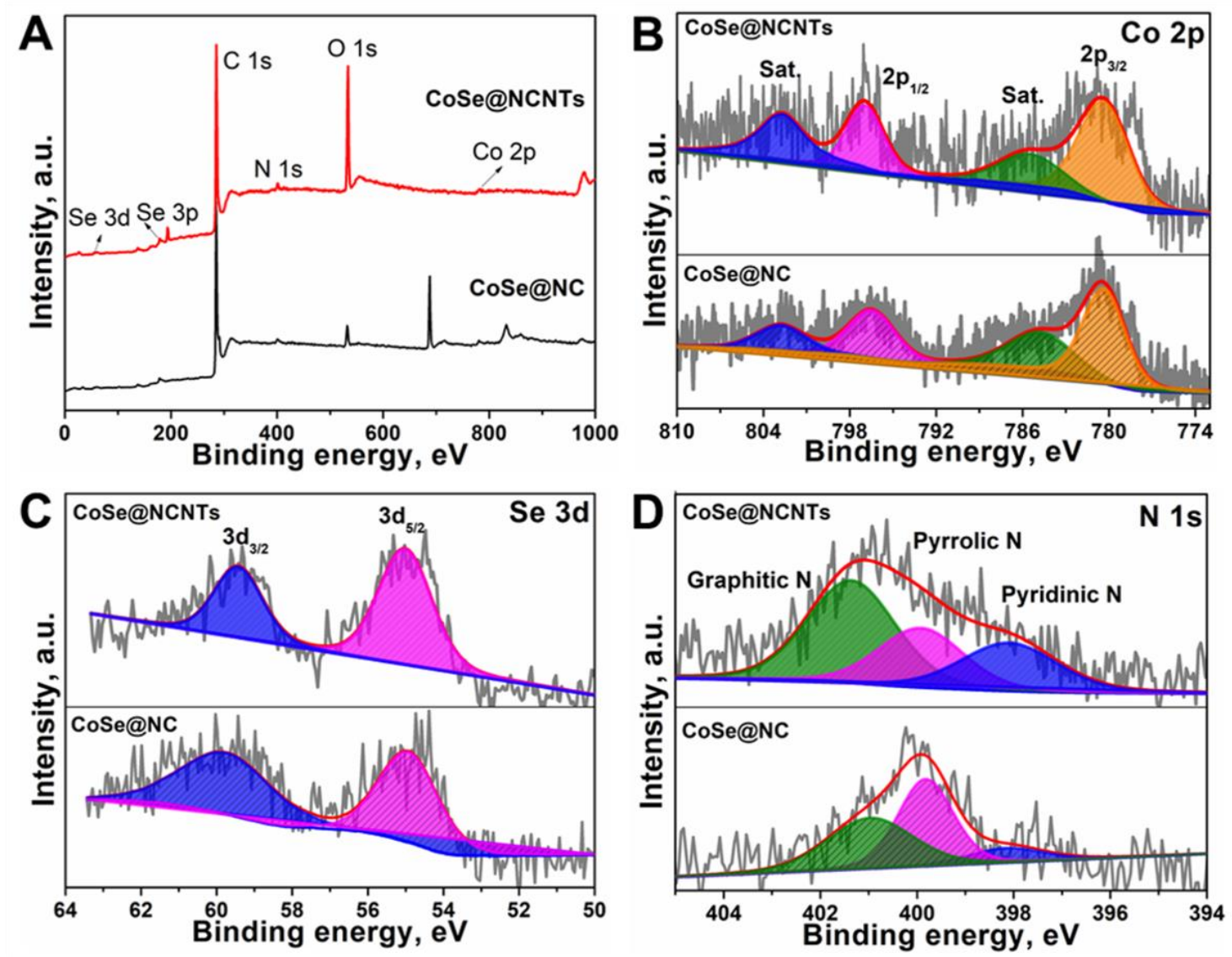

Figure S5. XPS survey spectra (A) and high-resolution XPS spectra of Co $2 p(B)$, Se 3d (C), and N 1s (D) for Co@NC and Co@NCNTs, respectively. 

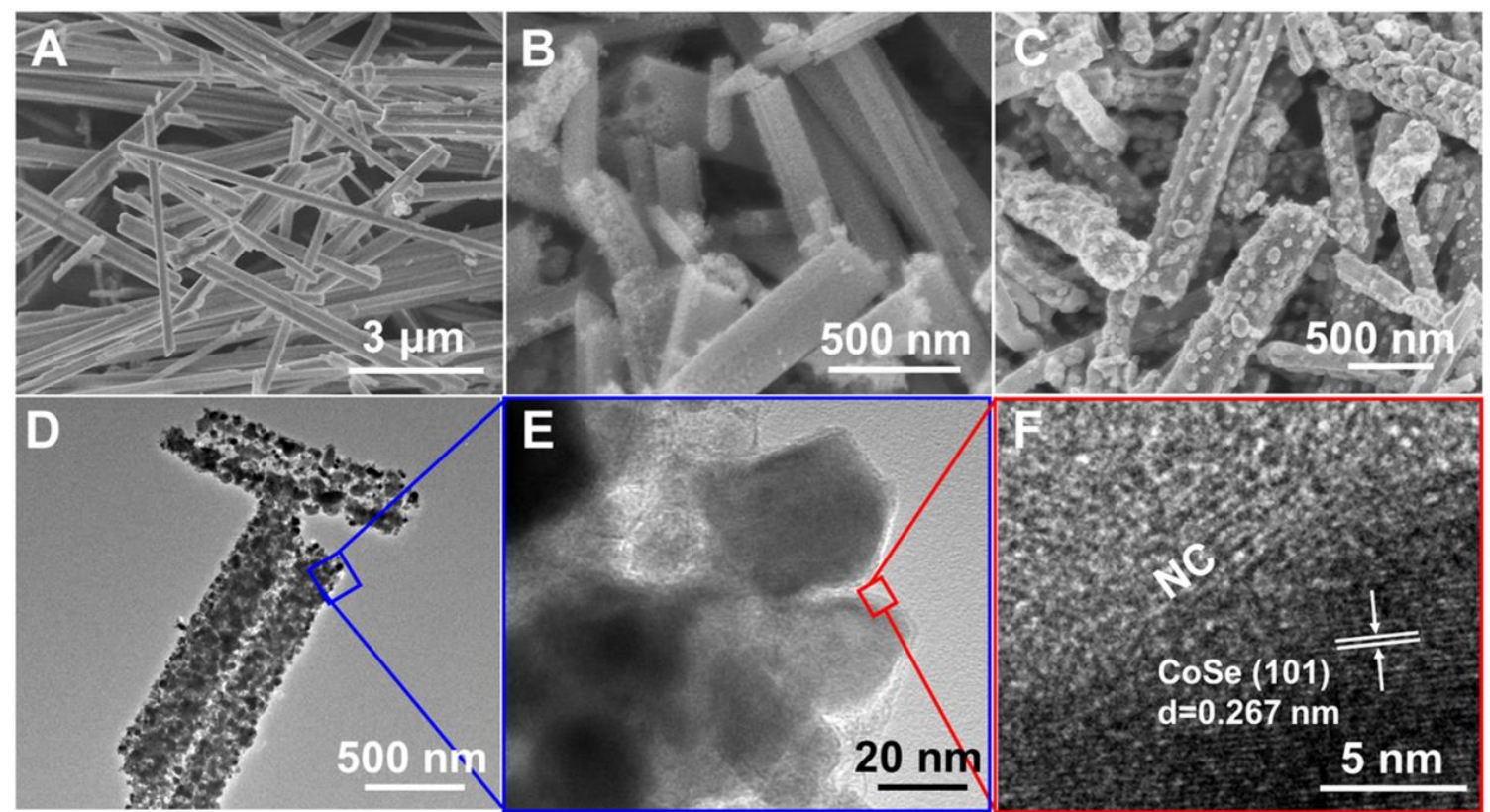

Figure S6. SEM images of Co-NTAC (A), Co@NC (B), and CoSe@NC (C). TEM (D, E) and HRTEM (F) images of CoSe@NC. 

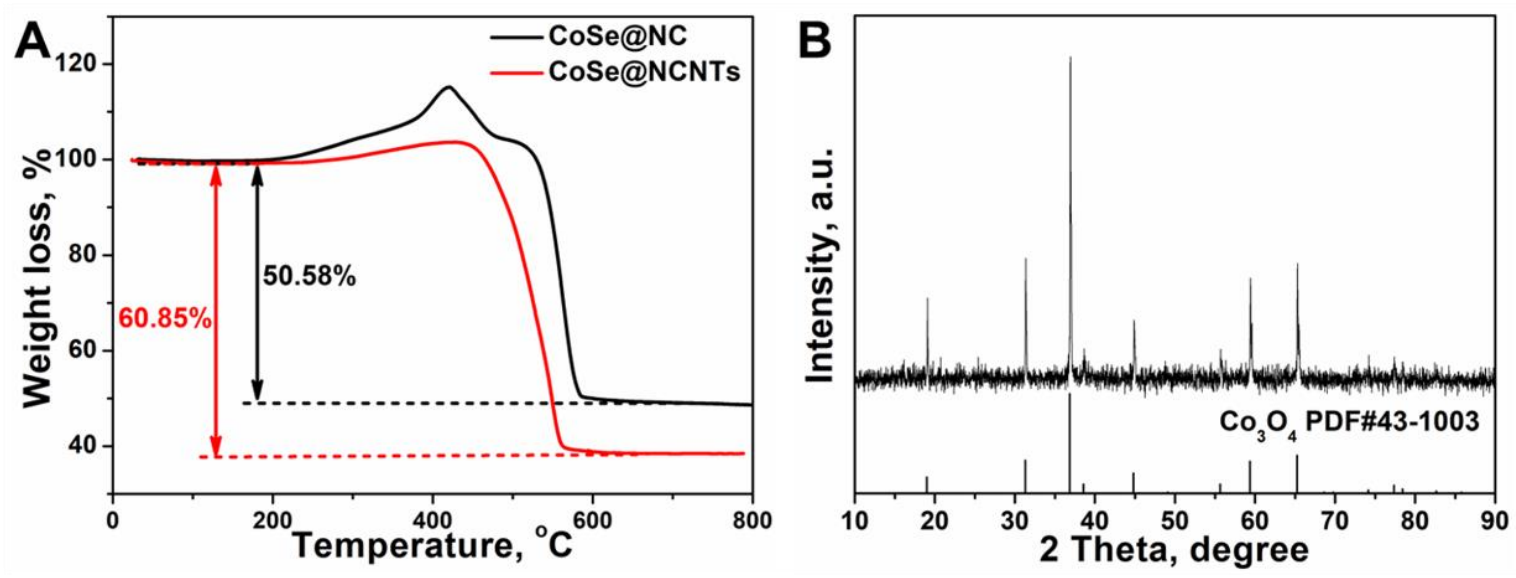

Figure S7. TGA curves of CoSe@NC and CoSe@NCNTs $(\mathrm{C})$. XRD pattern of the remains after TGA test, confirming the formation of $\mathrm{Co}_{3} \mathrm{O}_{4}(\mathrm{~B})$.

The calculation of carbon content in the composite: The weight loss below $200{ }^{\circ} \mathrm{C}$ was assigned to the loss of absorbed water. For CoSe@NC and CoSe@NCNTs, the weight loss above $800{ }^{\circ} \mathrm{C}$ is $50.58 \%$ and $60.85 \%$, respectively, which corresponds to the conversion of CoSe to $\mathrm{Co}_{3} \mathrm{O}_{4}$ and the combustion of carbon. Taking CoSe@NCNTs as an example, the content of carbon in CoSe@NCNTs composite is calculated based on the following conversion:

$$
\begin{aligned}
& \mathrm{CoSe} @ \mathrm{NCNTs} \rightarrow \mathrm{Co}_{3} \mathrm{O}_{4}+\text { gas } \\
& \text { Atomic weight: } \mathrm{Co}(59), \mathrm{Se}(79), \mathrm{O}(16) \\
& \mathrm{x}+\frac{[(59+79)-(59 * 3+16 * 4) / 3](1-\mathrm{x})}{(59+79)}=60.85 \%
\end{aligned}
$$

The total weight percentage of CoSe@NCNTs composite is taken as 100\%, while the carbon weight percentage is $\mathrm{x}$. The weight loss percentage of conversion between $\mathrm{CoSe}$ and $\mathrm{Co}_{3} \mathrm{O}_{4}$ is

$$
\frac{[(59+79)-(59 * 3+16 * 4) / 3](1-x)}{(59+79)}=\frac{173(1-x)}{414}
$$

from which the carbon content $\mathrm{x}$ in $\mathrm{CoSe} @$ NCNTs is calculated to be $32.73 \%$. In the same way, the carbon content in $\mathrm{CoSe} @ \mathrm{NC}$ is calculated to be $15.08 \%$. 

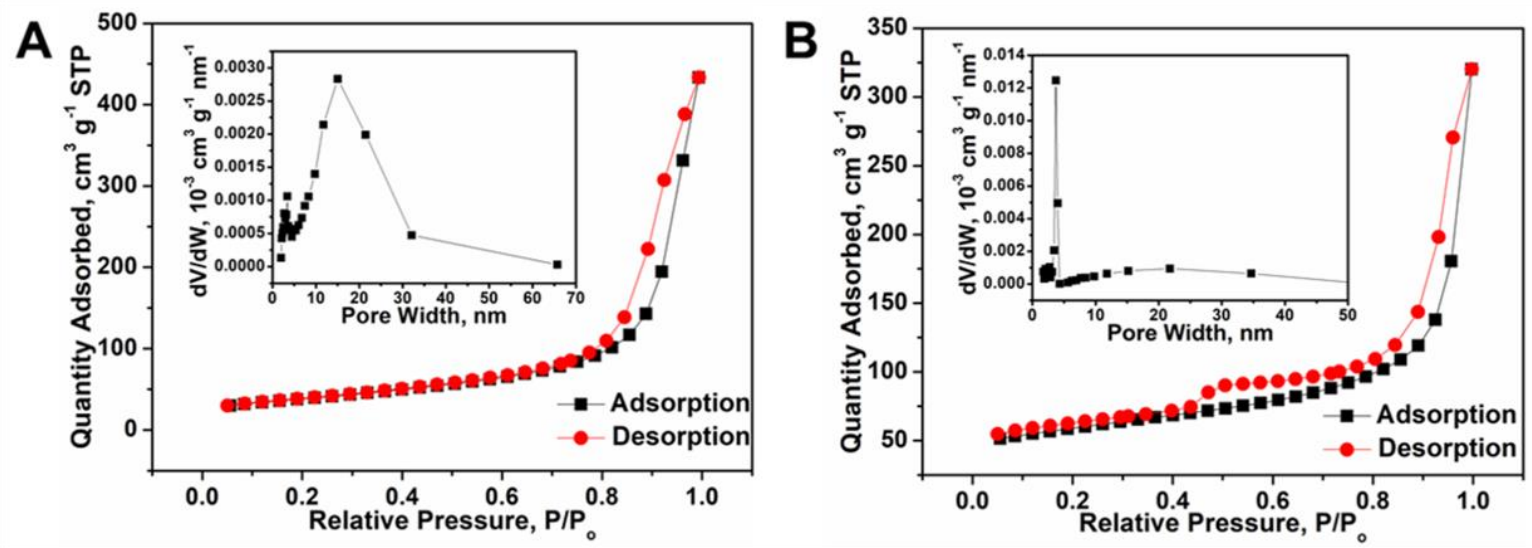

Figure S8. $\mathrm{N}_{2}$ adsorption/desorption isotherm and corresponding pore size distribution (inset) of the Co@NC (A) and Co@NCNTs (B), respectively. 


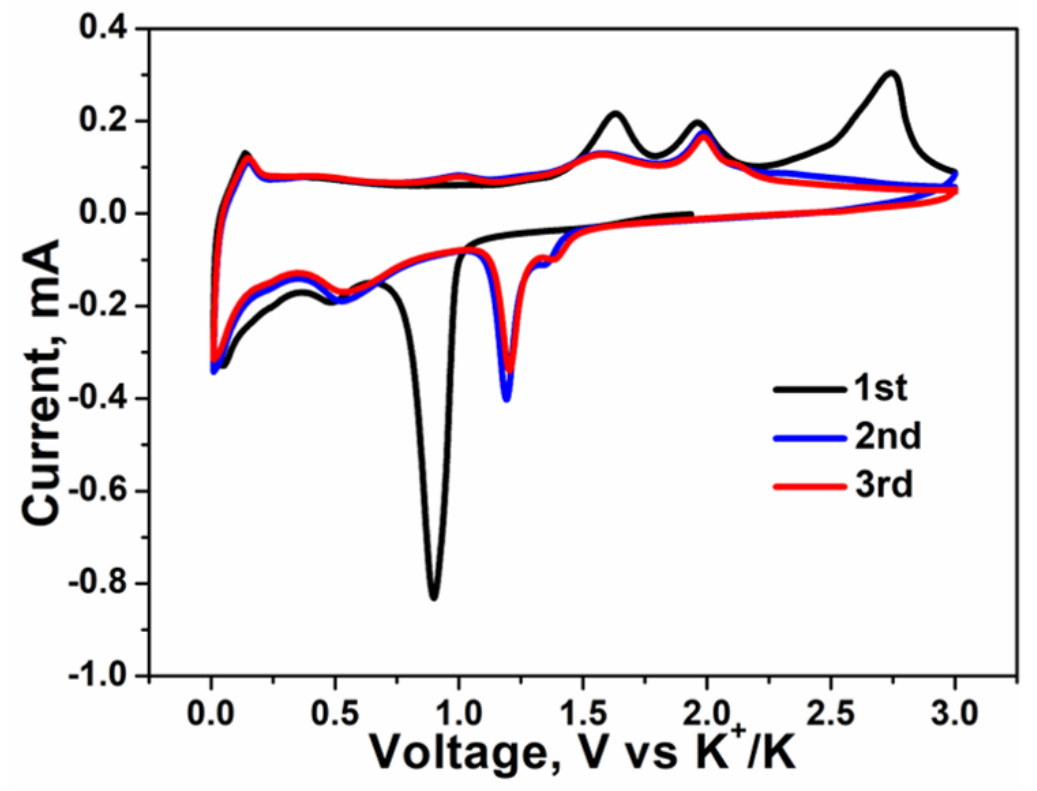

Figure S9. Cyclic voltammetry (CV) curves of CoSe@NC at a scan rate of $0.2 \mathrm{mV} \mathrm{s}^{-1}$ within a voltage range of $0.01-3.0 \mathrm{~V}$ 

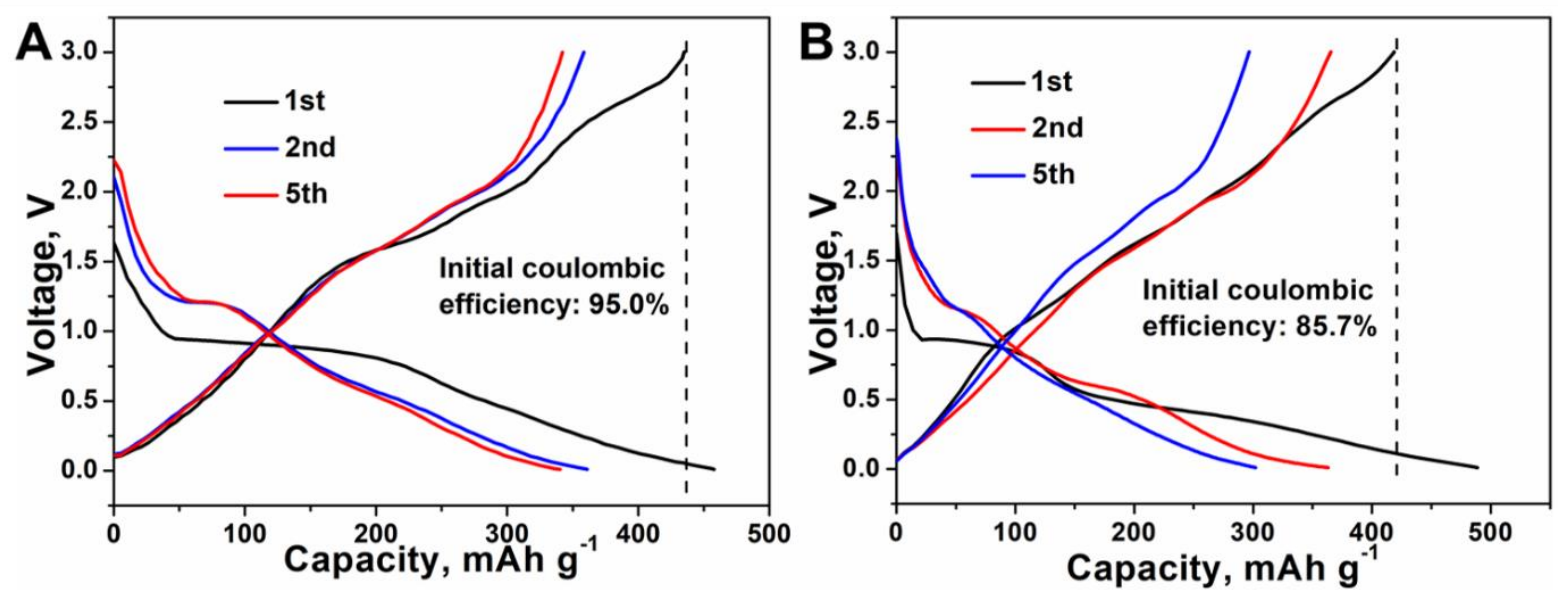

Figure S10. Charge/discharge curves of different cycles for CoSe@NCNTs (A) and CoSe@NC (B) with $1 \mathrm{M} \mathrm{KPF} 6$ in DME as electrolyte. 

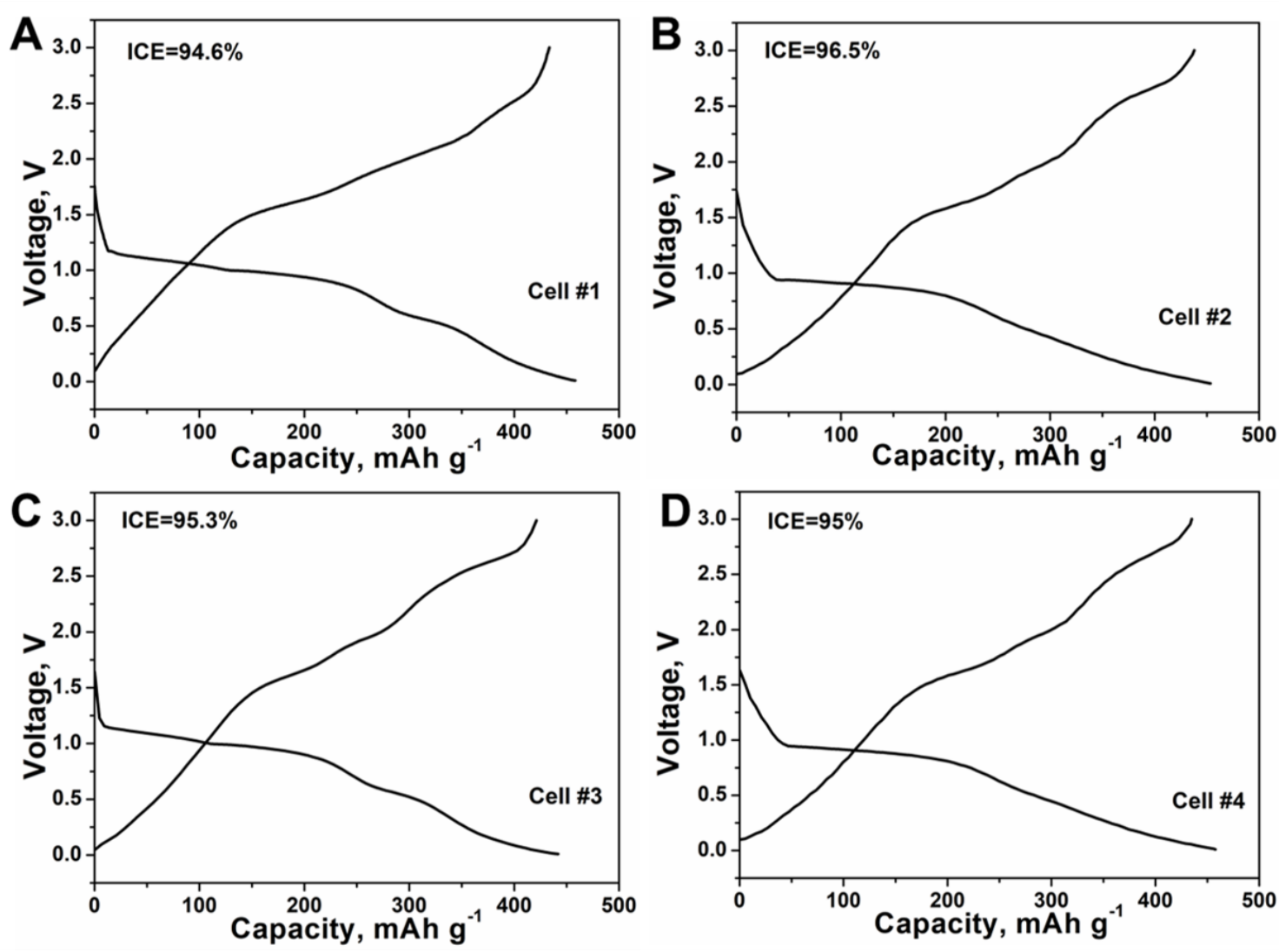

Figure S11. Initial charge/discharge profiles at $0.1 \mathrm{Ag}^{-1}$ and the initial Coulombic efficiency (ICE) for the four different batteries with CoSe@NCNTs as anode and 1 M KPF6 in DME $\left(\mathrm{KPF}_{6}-\mathrm{DME}\right)$ as electrolyte. 
Table S1. Comparison of the ICEs and cycling performance of the reported TMCs-based PIB anode materials for and that of CoSe@NCNTs fabricated in this work.

\begin{tabular}{cccccc}
\hline Sample & $\begin{array}{c}\text { Cycle } \\
\text { number }\end{array}$ & $\begin{array}{c}\text { Current } \\
\text { density } \\
\left(\mathrm{Ag}^{-1}\right)\end{array}$ & $\begin{array}{c}\text { Capacity } \\
\text { retention } \\
(\%)\end{array}$ & $\begin{array}{c}\text { Initial } \\
\text { coulombic } \\
\text { efficiency } \\
(\%)\end{array}$ & Reference \\
\hline $\begin{array}{c}\text { N-doped CNTs } \\
\text { framework@CoSe } 2\end{array}$ & 100 & 0.2 & 85.3 & 69.3 & S1 \\
$\begin{array}{c}\text { CoS@graphene } \\
\text { Graphene@yolk- } \\
\text { shell FeS } @ \text { C }\end{array}$ & 100 & 0.5 & 70.2 & 64.4 & S2 \\
MoSe2/C & 100 & 0.2 & 83.9 & 63.4 & S3 \\
V5S8@C & 100 & 0.05 & 80 & 64 & S5 \\
VSe 2 & - & 0.2 & - & 69.1 & S6 \\
SnS @rGO & 100 & 0.05 & 87 & 51.2 & S7 \\
WS 2 & 100 & 0.005 & 84.5 & 56.6 & S8 \\
CuSe & 40 & 0.2 & 86 & 92.4 & S9 \\
CoSe@NCNTs & 100 & 0.5 & 89.3 & 94.8 & This work \\
\hline
\end{tabular}




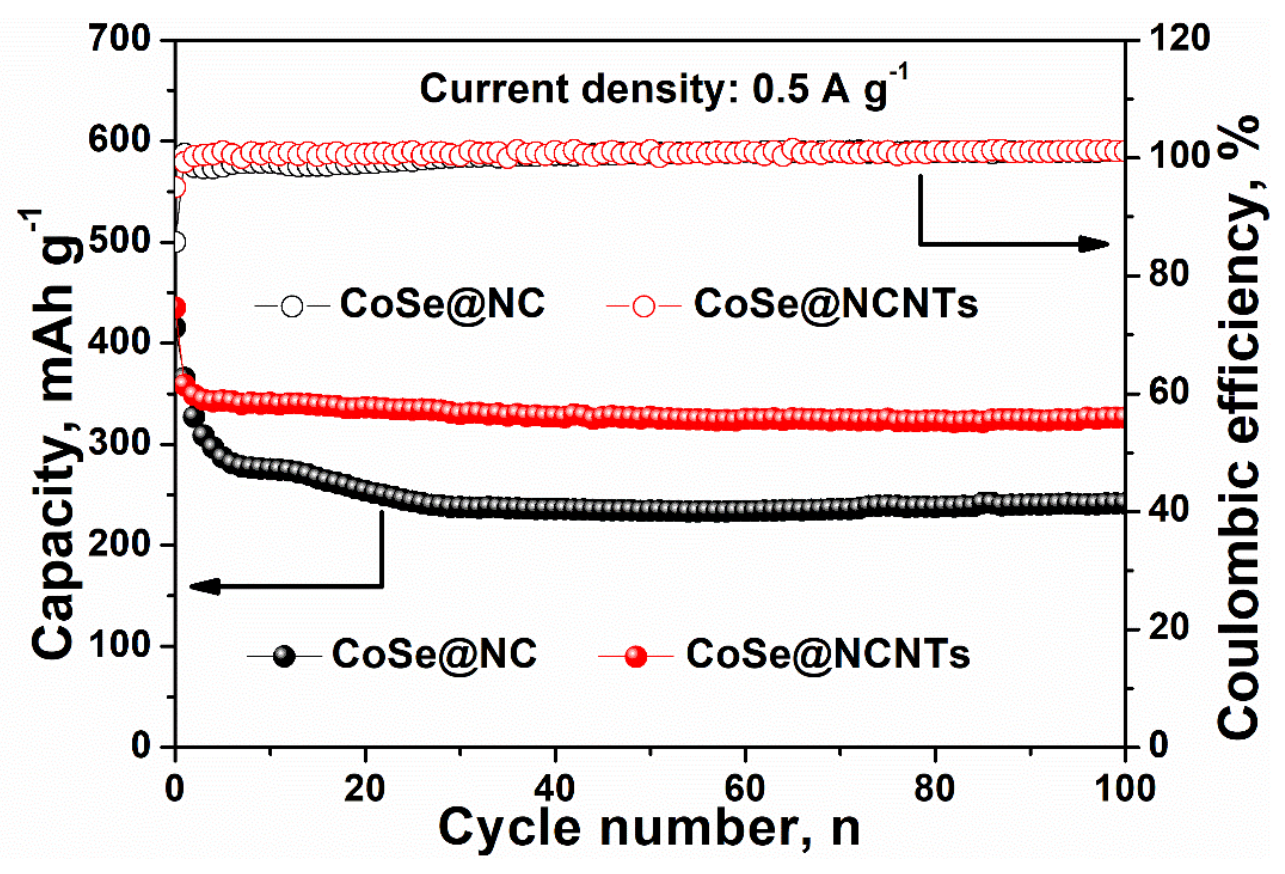

Figure S12. Cycling performance of CoSe@NC and CoSe@NCNTs composites at $0.5 \mathrm{~A} \mathrm{~g}^{-1}$, the active materials were initially activated at $0.1 \mathrm{~A} \mathrm{~g}^{-1}$. 

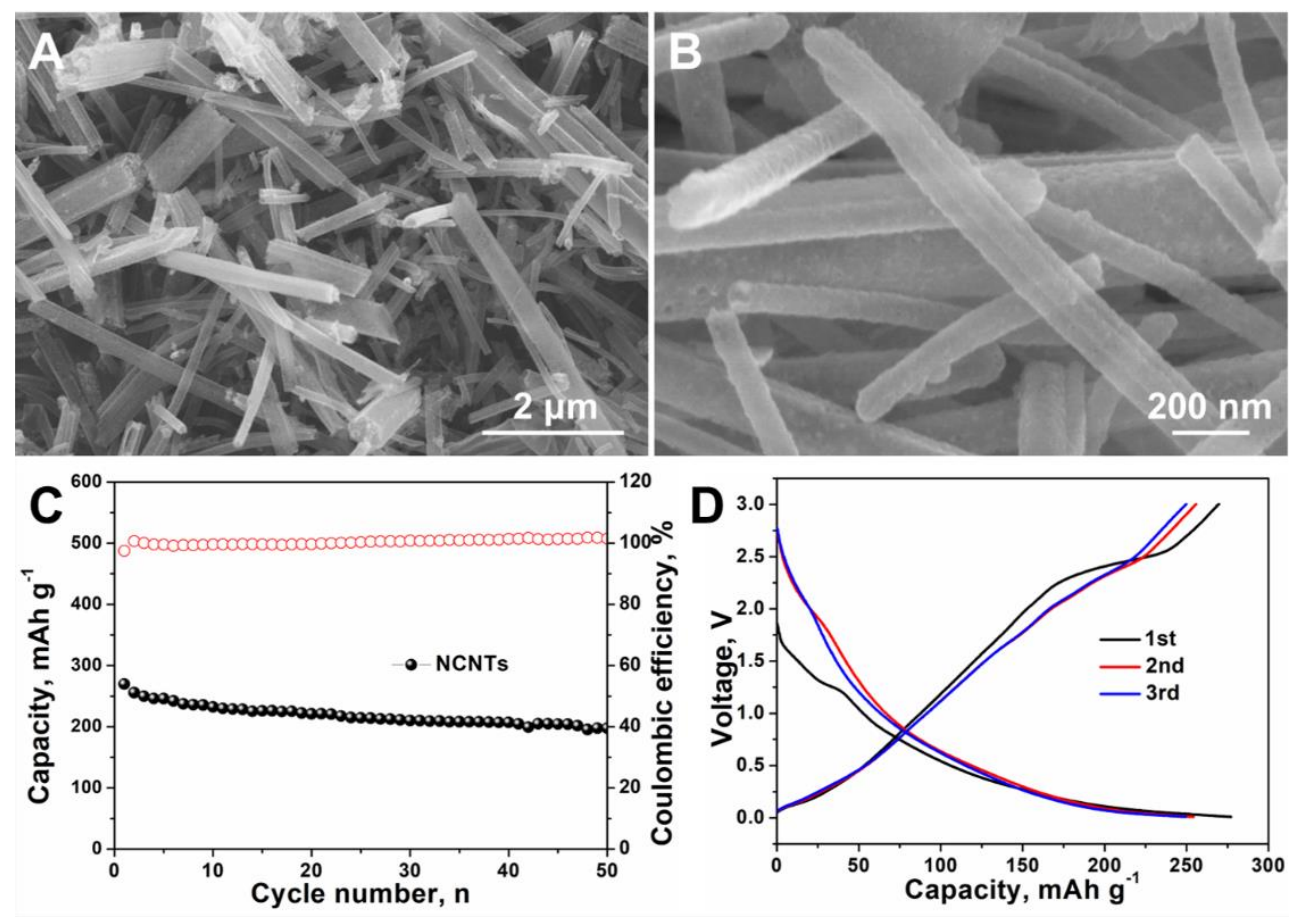

Figure S13. SEM images of bare NCNTs sample (A, B). Cycling performance (C) and discharge and charge profiles (D) of bare NCNTs sample at $0.5 \mathrm{~A} \mathrm{~g}^{-1}$ in KPF6-DME electrolyte.

A bare NCNTs sample was synthesized by dissolving Co@ NCNTs powder in $2 \mathrm{M} \mathrm{HCl}$ solution for $48 \mathrm{~h}$, washing with distilled water for several times and drying overnight in a vacuum oven at $80^{\circ} \mathrm{C}$. The SEM images are shown in Figure S13, where it is evident that after Co removal, the tubular morphology of NCNT is still maintained. According to the NCNTs loading (32.73\%) in the composite and the second cycle charge capacity $\left(256 \mathrm{~mA} \mathrm{~h} \mathrm{~g}^{-1}\right)$ of bare NCNTs, the capacity contribution from NCNTs in CoSe@NCNTs composite is estimated to be around $83.8 \mathrm{~mA} \mathrm{~h} \mathrm{~g}^{-1}$. 

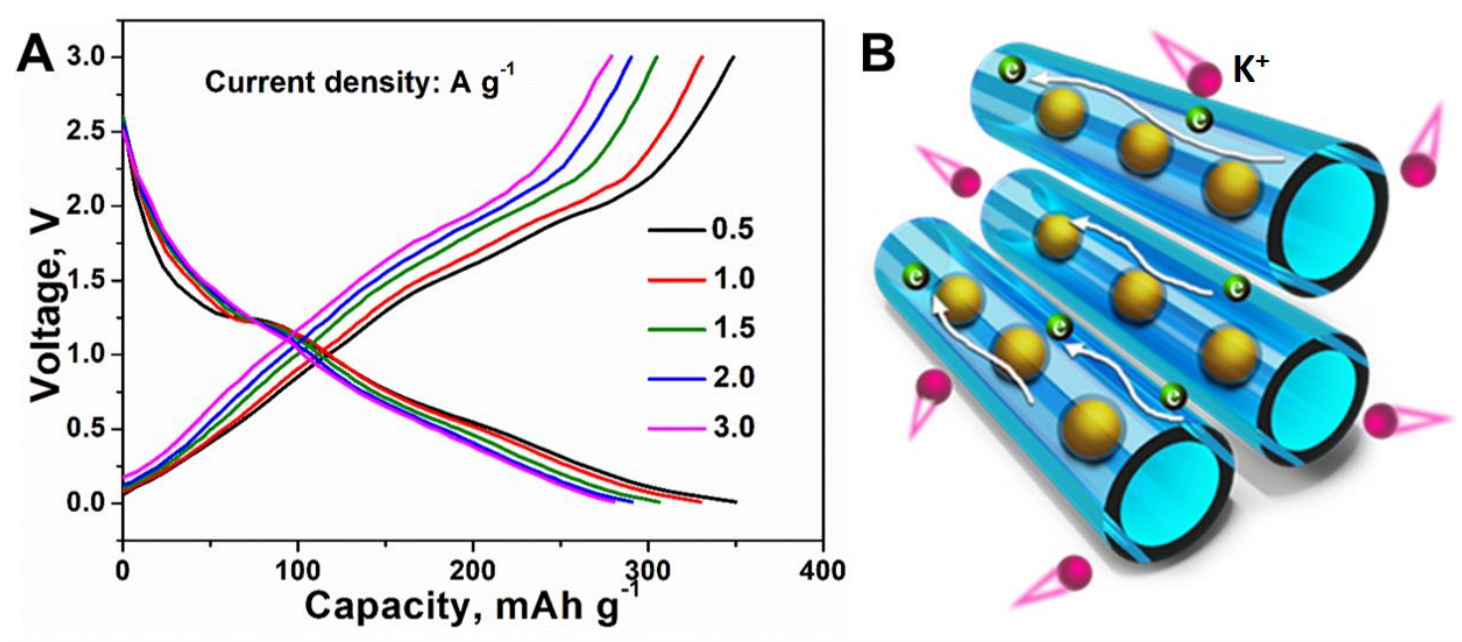

Figure S14. The discharge/charge profiles of CoSe@NCNTs at different current densities (A).

Schematic diagram of electron/ion transportation of CoSe@NCNTs (B). 


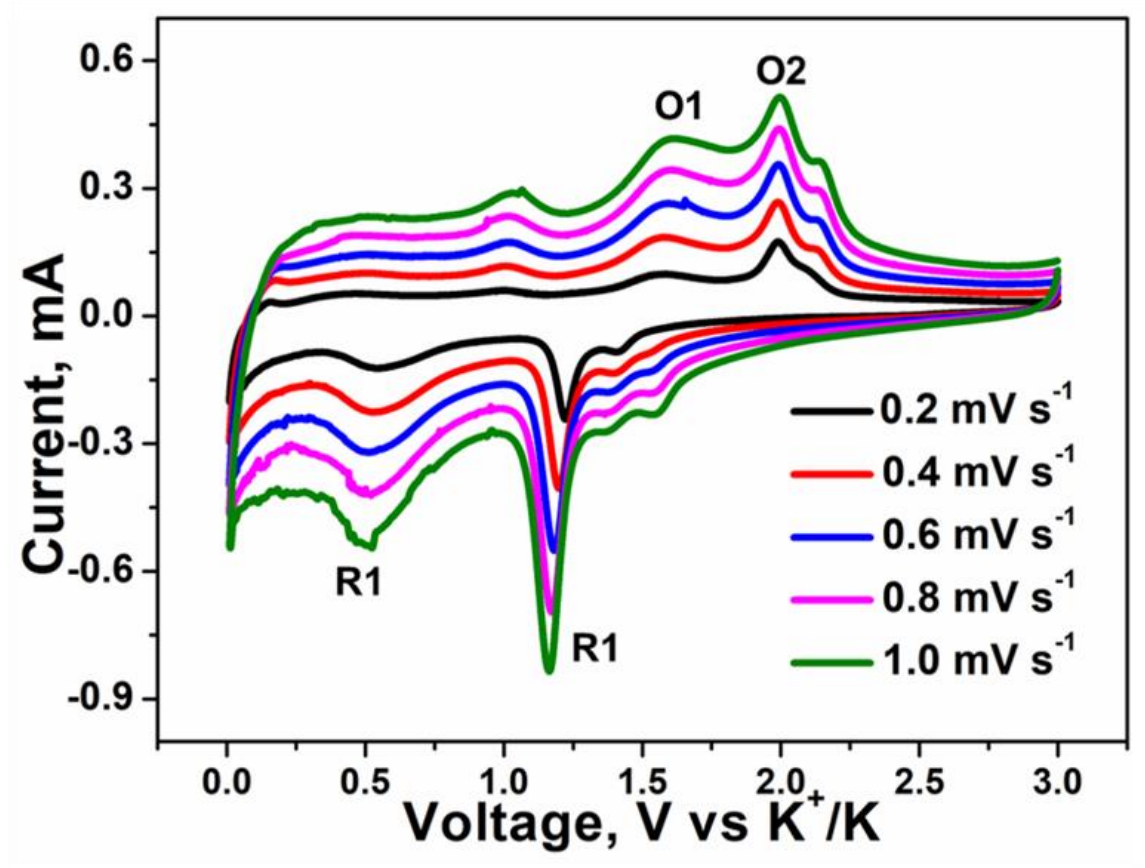

Figure S15. CV curves of CoSe@NCNTs at various scan rates of 0.2 to $1.0 \mathrm{mV} \mathrm{s}^{-1}$ within the voltage range of 0.01-3.0 V. 

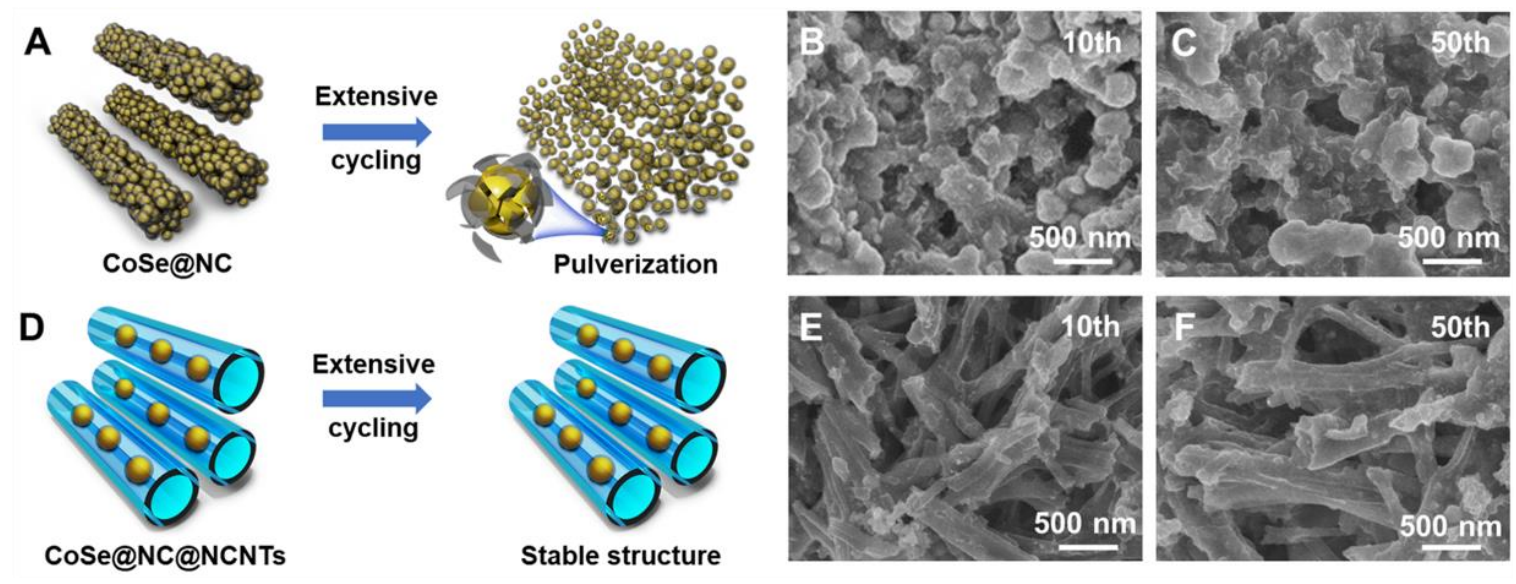

Figure S16. Illustration of the proposed stabilizing effect and SEM images for CoSe@ NC (AC) and CoSe@NCNTs (D-F) anodes after different cycles at $0.5 \mathrm{~A} \mathrm{~g}^{-1}$. 


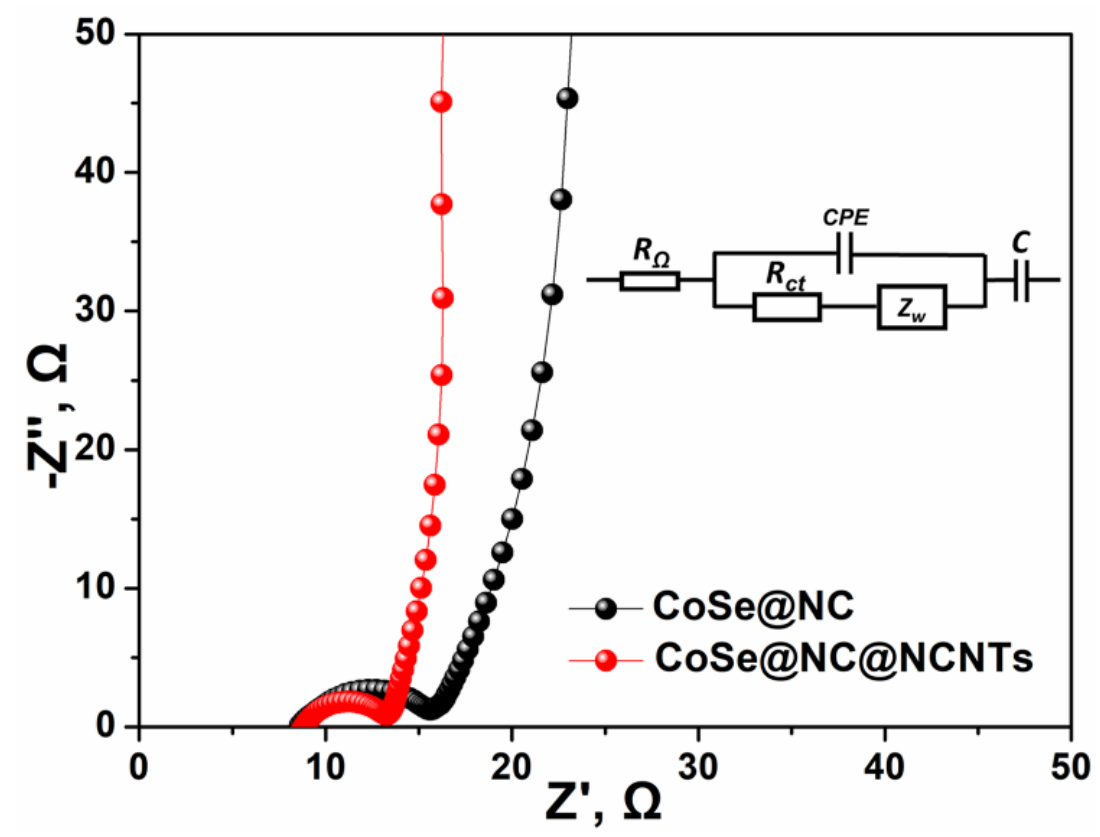

Figure S17. Nyquist plots of CoSe@NC and CoSe@NCNTs; inset: equivalent circuit model. 

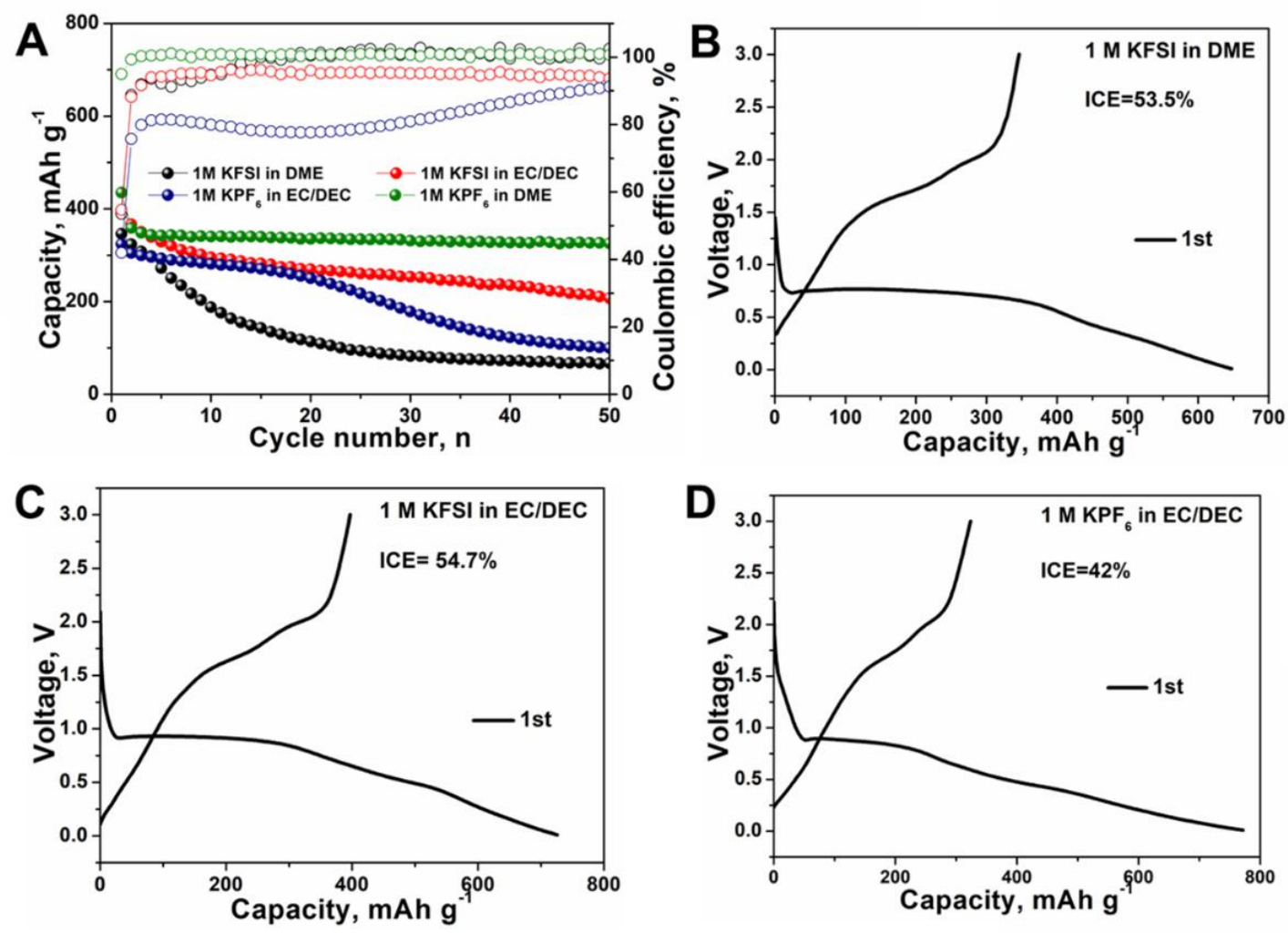

Figure S18. Cycle performance of CoSe@NCNTs at $0.5 \mathrm{~A} \mathrm{~g}^{-1}$ with different electrolytes $(1 \mathrm{M}$ KFSI in DME, $1 \mathrm{M}$ KFSI in EC/DEC, $1 \mathrm{M} \mathrm{KPF} 6$ in EC/DEC, and $1 \mathrm{M} \mathrm{KPF} 6$ in DME) (A), the initial discharge/charge profiles with different electrolytes and the corresponding ICE (B-D) of CoSe@NCNTs. 


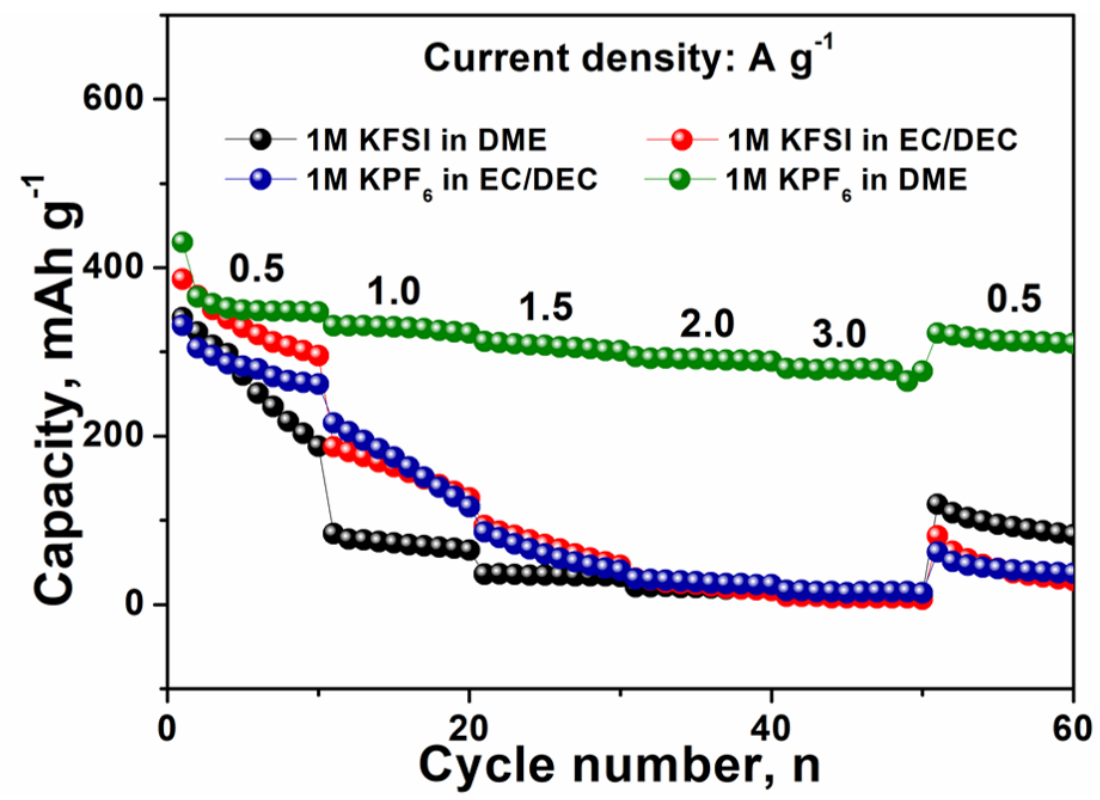

Figure S19. Rate performance of CoSe@ NCNTs with different electrolytes (1 M KFSI in DME, $1 \mathrm{M}$ KFSI in EC/DEC, $1 \mathrm{M} \mathrm{KPF} 6$ in EC/DEC, and $1 \mathrm{M} \mathrm{KPF} 6$ in DME) 

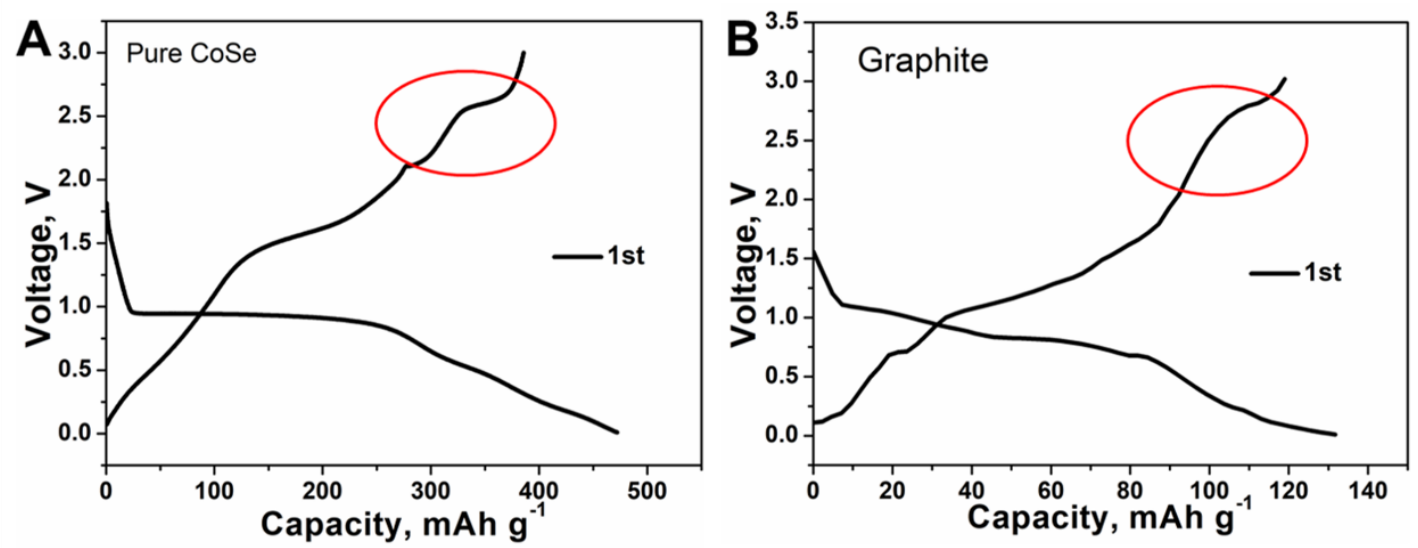

Figure S20. Discharge/charge profiles at $0.1 \mathrm{~A} \mathrm{~g}^{-1}$ of pure CoSe (A) and graphite (B). 

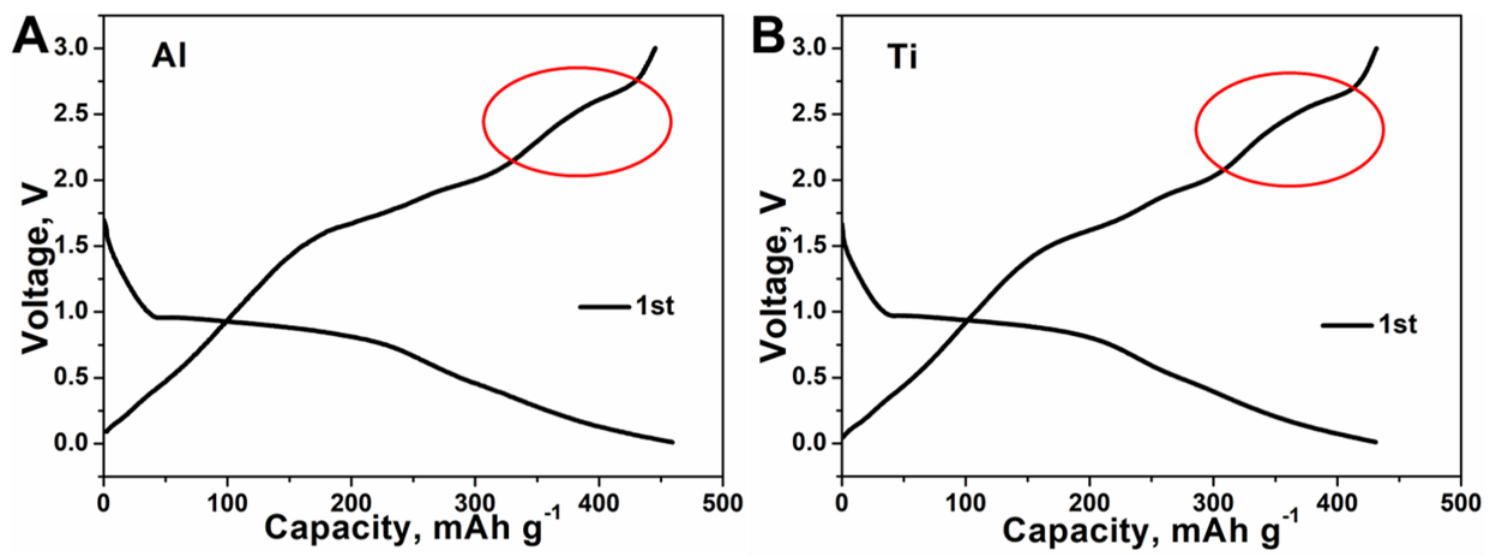

Figure S21. Discharge/charge profiles at $0.1 \mathrm{~A} \mathrm{~g}^{-1}$ of CoSe@NCNTs with Al foil (A) and Ti foil (B) as the current collector. 

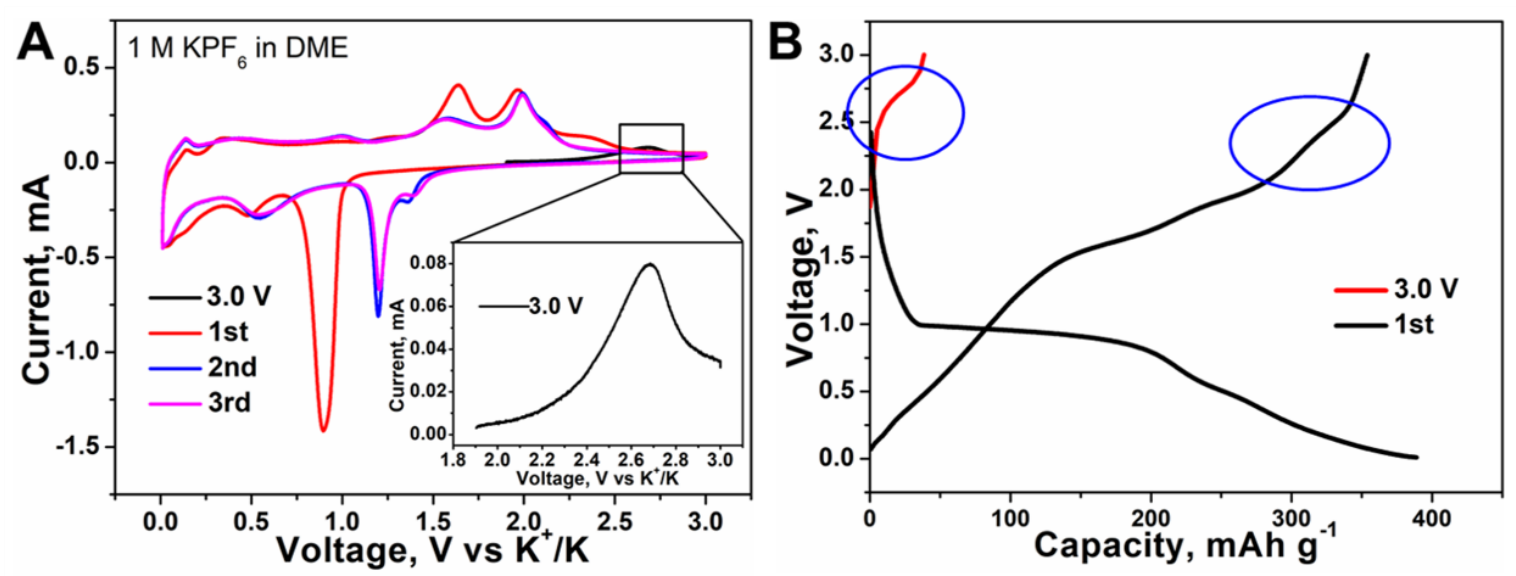

Figure S22. CV curves (A) and discharge/charge profiles (B) through charging to $3.0 \mathrm{~V}$ in the first step of CoSe@NCNTs in 1 M KPF6 in DME electrolyte. 

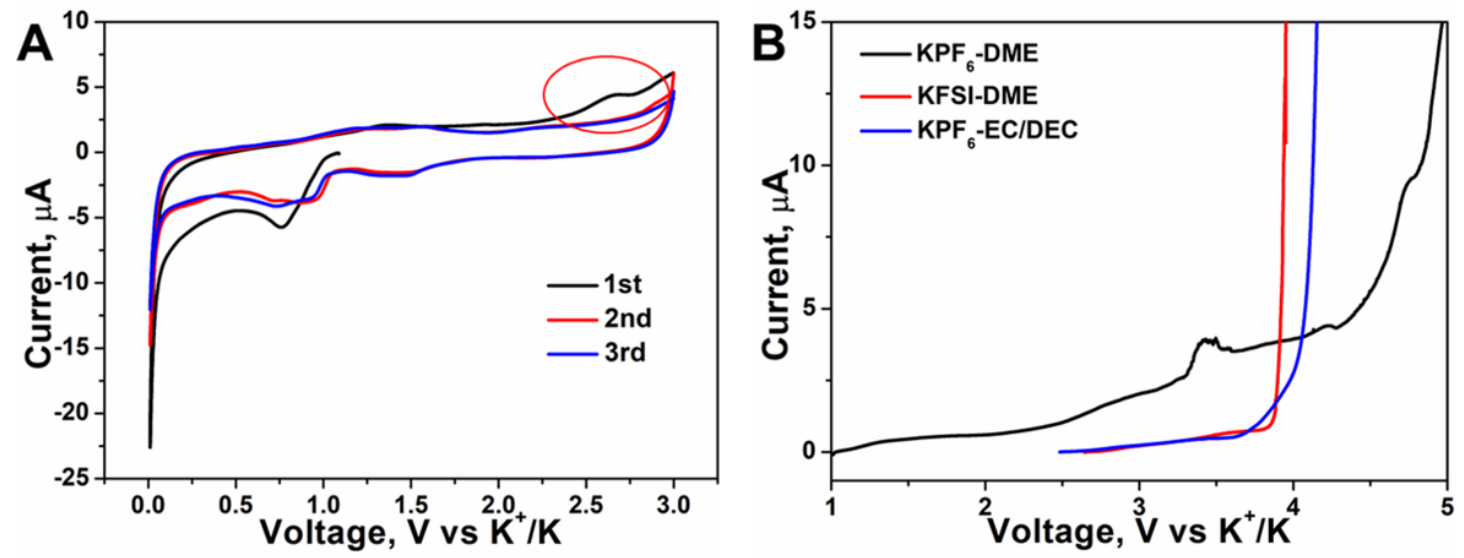

Figure S23. Cyclic voltammetry $(\mathrm{CV})$ curves of $\mathrm{K}-\mathrm{Cu}$ foil cell with $1 \mathrm{M} \mathrm{KPF} 6$ in $\mathrm{DME}$ as electrolyte at $0.2 \mathrm{mV} \mathrm{s}^{-1}(\mathrm{~A})$, and $\mathrm{CV}$ curves of the cells composed of K/Electrolyte/Al foil (KPF6-DME: $1 \mathrm{M}$ KPF6 in DME, KFSI-DME: $1 \mathrm{M}$ KFSI in DME, KPF6-EC/DEC: $1 \mathrm{M}$ KPF6 in $\mathrm{EC} / \mathrm{DEC})(\mathrm{B})$. 


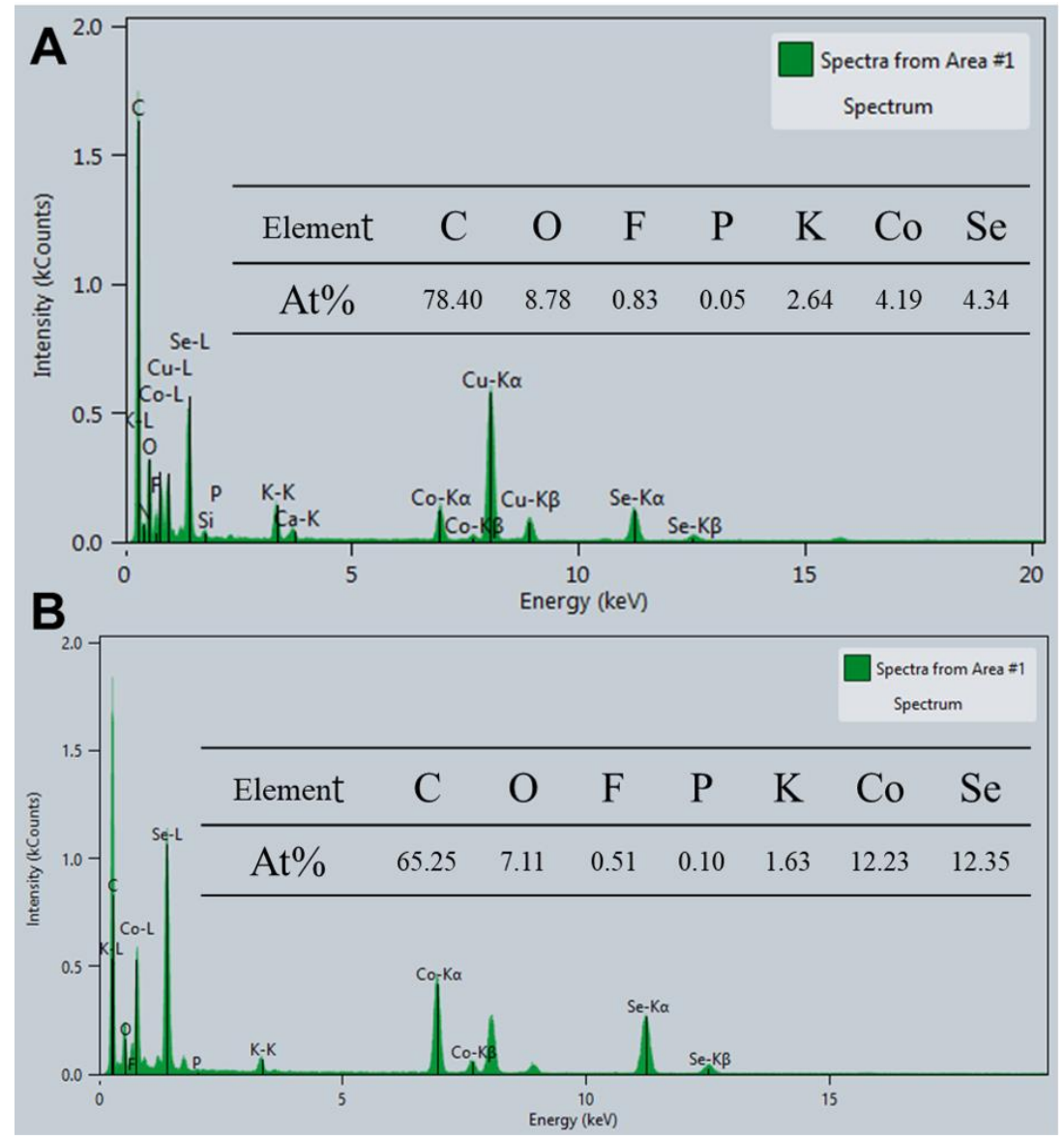

Figure S24. EDS spectrum and elemental ratio (inset) of CoSe@NCNTs after discharged to $0.01 \mathrm{~V}(\mathrm{~A})$ and charged to $3.0 \mathrm{~V}(\mathrm{~B})$ during the initial cycle. 

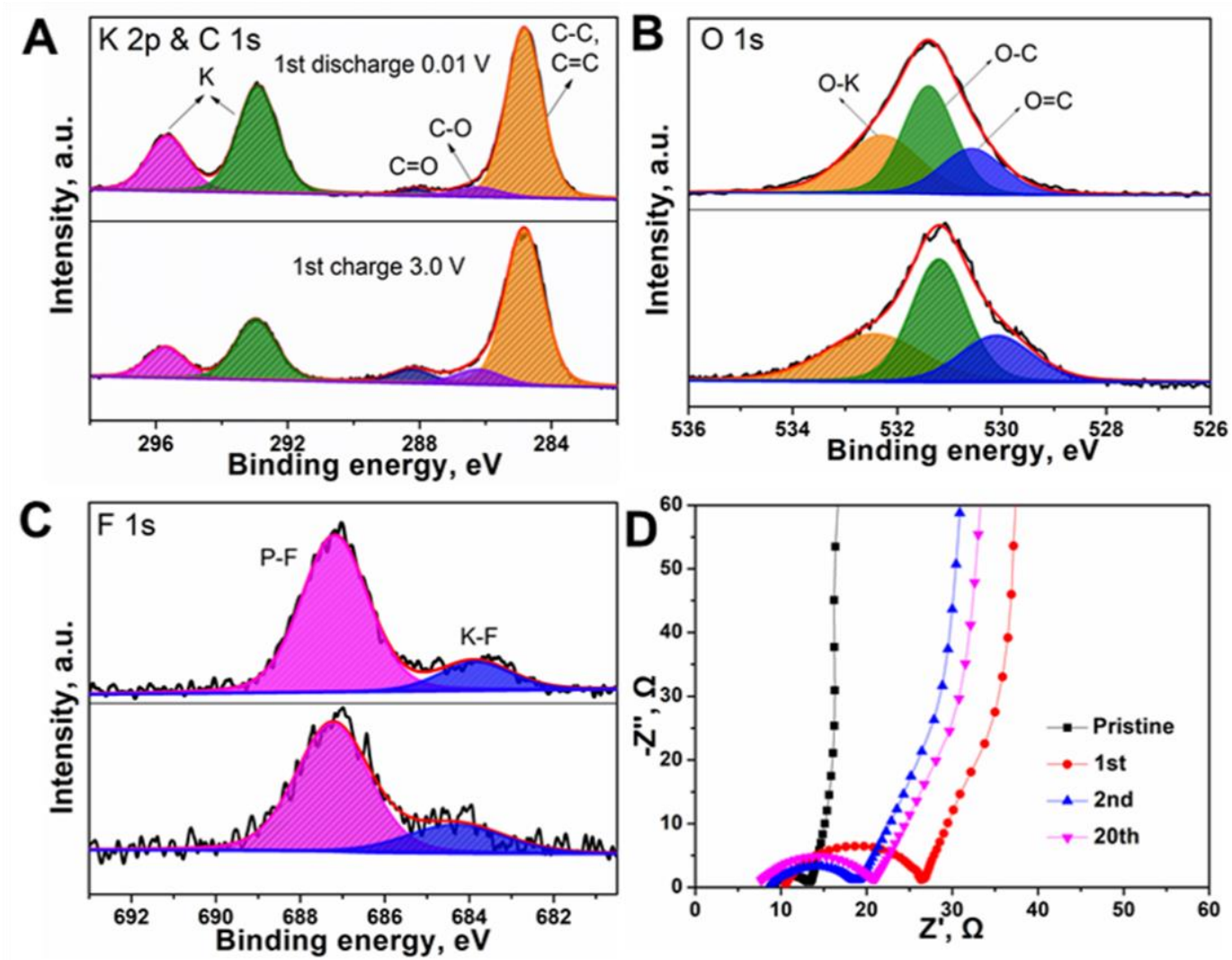

Figure S25. High-resolution XPS spectra of K-2p and C-1s (A), O-1s (B), F-1s (C) for CoSe@NCNTs in KPF6-DME electrolyte after discharged to $0.01 \mathrm{~V}$ and charged to $3.0 \mathrm{~V}$ in the first cycle. The Nyquist plots of pristine CoSe@NCNTs and after different cycles in KPF6DME electrolyte (D). 

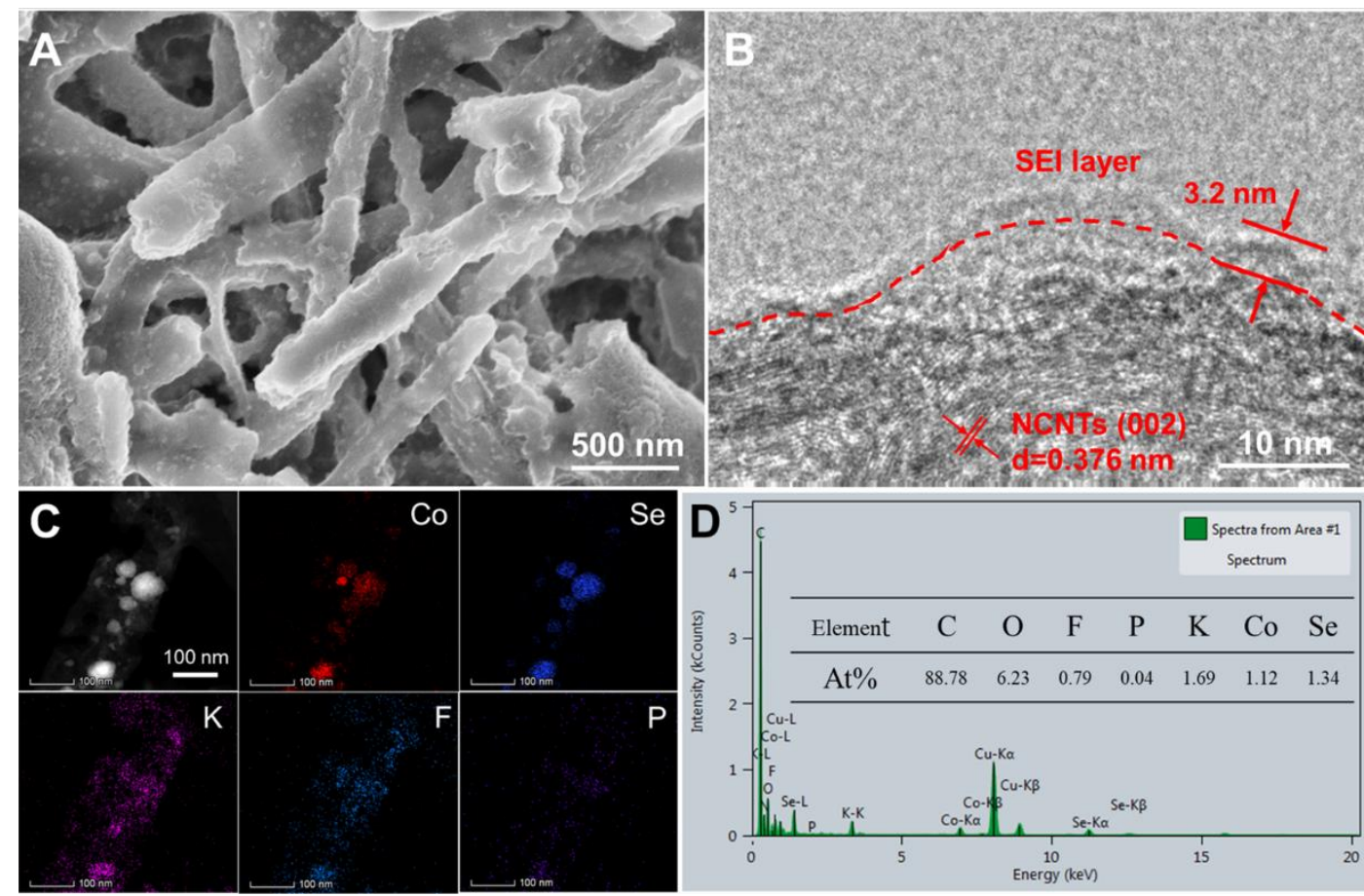

Figure S26. SEM images (A), HRTEM images (B), TEM image and corresponding elemental mappings (C), EDS spectrum and the elemental ratio (inset) (D) of CoSe@ NCNTs after 20th cycles at $0.5 \mathrm{~A} \mathrm{~g} \mathrm{~g}^{-1}$ in the electrolyte of $1 \mathrm{M} \mathrm{KPF}_{6}$ in DME. 


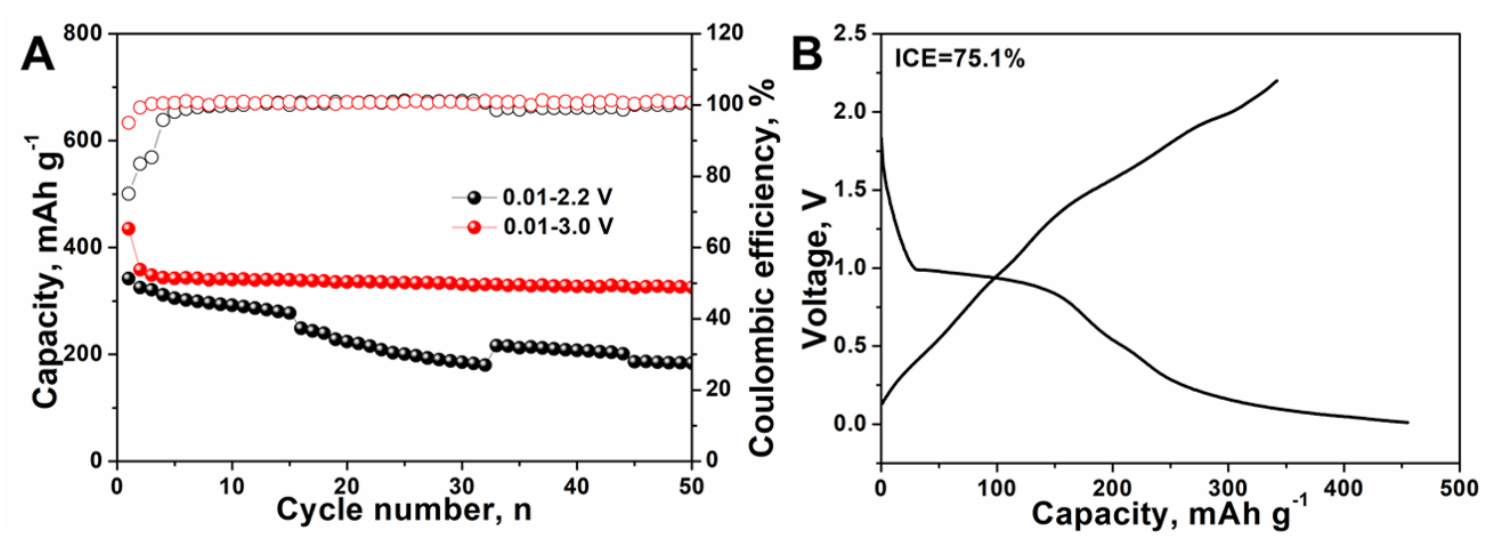

Figure S27. Cycle performance of CoSe@NCNTs at $0.5 \mathrm{~A} \mathrm{~g}^{-1}$ within different voltage range in KPF6-DME electrolyte (A). Initial charge/discharge profiles at $0.1 \mathrm{~A} \mathrm{~g}^{-1}$ of CoSe@NCNTs within a voltage range of 0.01-2.2 V (B). 

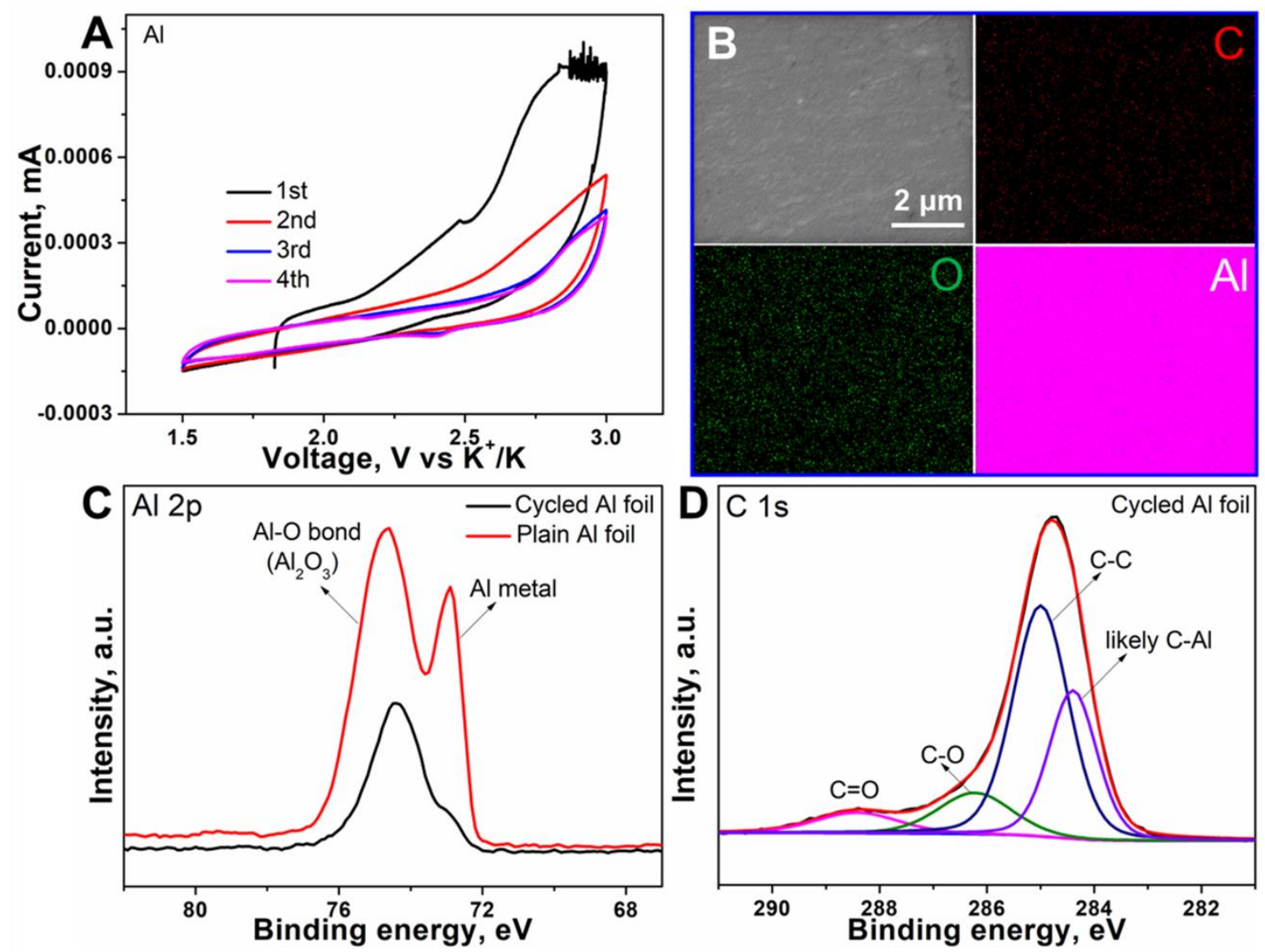

Figure S28. CV curves of K-Al foil cell in $\mathrm{KPF}_{6}-\mathrm{DME}$ electrolyte at $0.2 \mathrm{mV} \mathrm{s}^{-1}$ in the voltage range of 1.5-3.0 V (A). SEM image and corresponding $\mathrm{C}$, $\mathrm{O}$, and $\mathrm{Al}$ element mapping images of the cycled Al foil after CV test (B). High-resolution XPS spectra of Al-2p for plain Al foil and the cycled Al foil (C); High-resolution XPS spectra of C-1s for the cycled Al foil (D); 


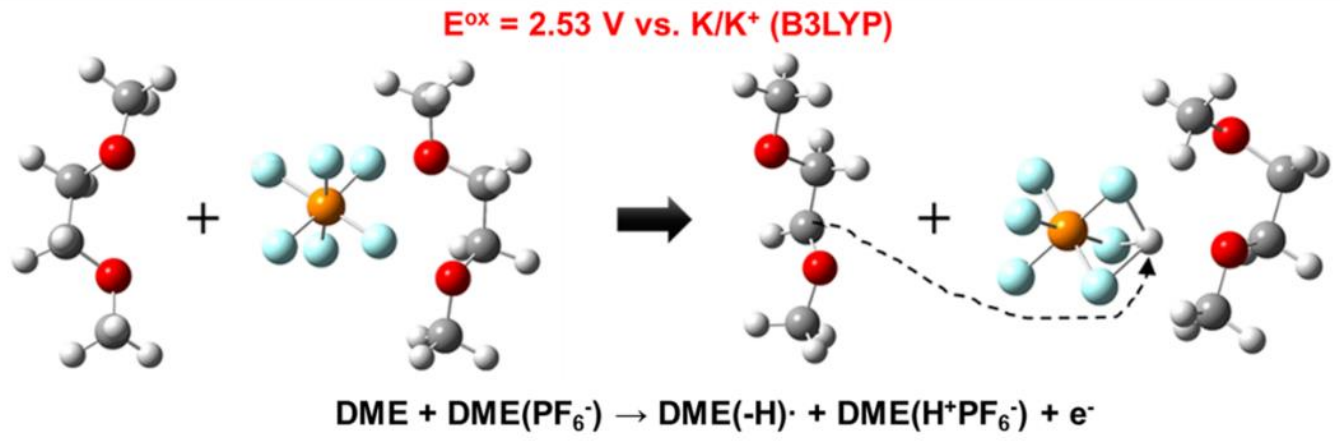

Figure S29A. DME oxidation with $\mathrm{PF}_{6}{ }^{-}$anion from B3LYP calculations. 


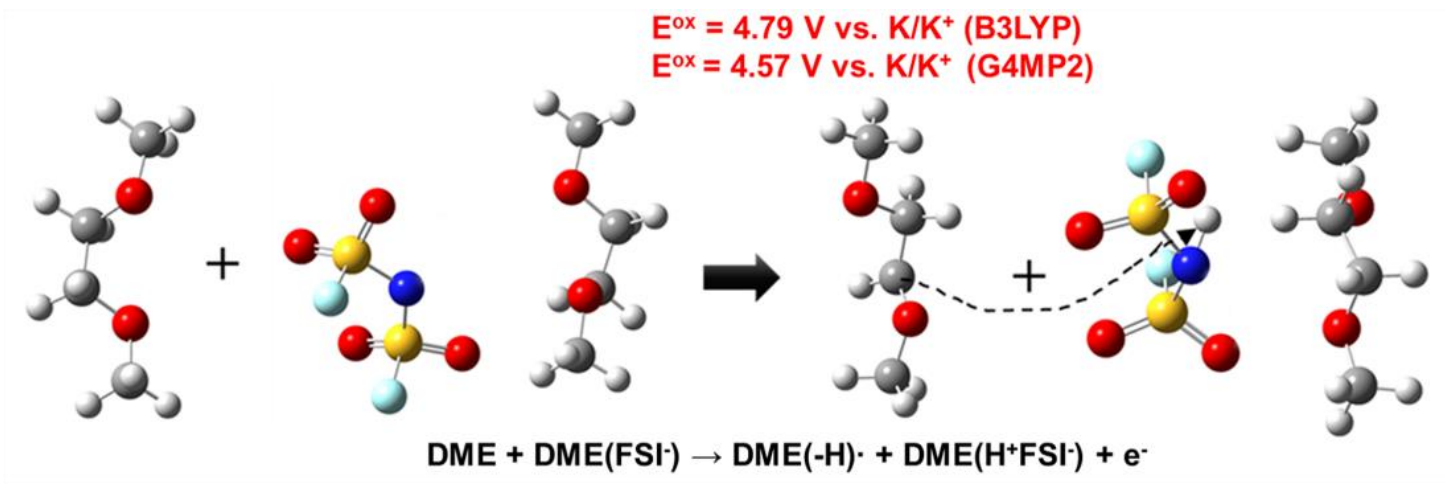

Figure S29B. DME oxidation with FSI- anion from B3LYP and G4MP2 calculations. 


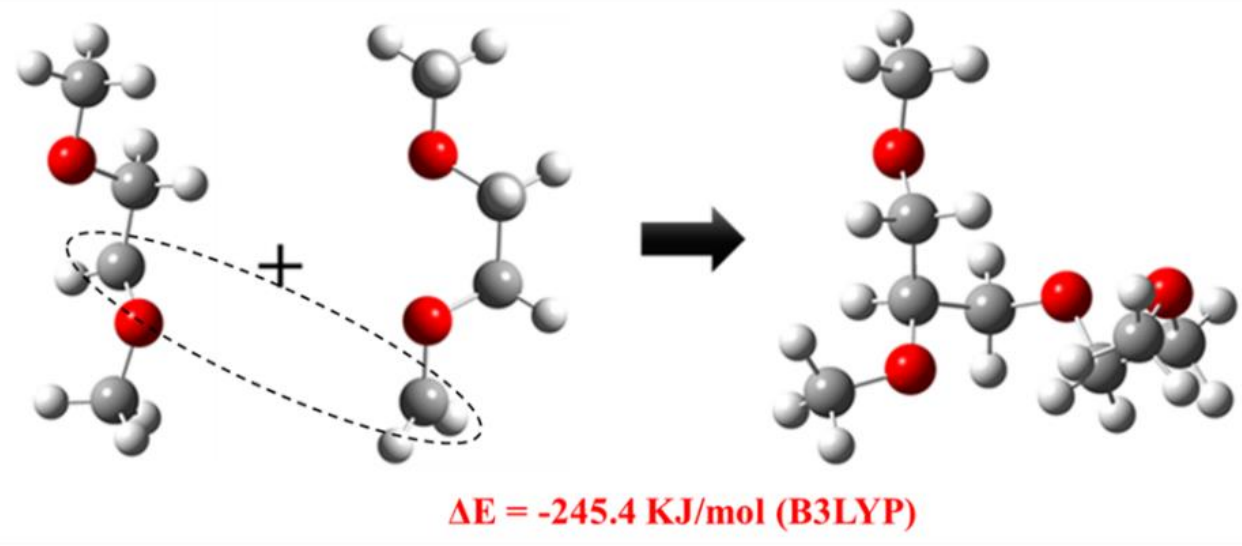

Figure S29C. Polymerization of two DME(-H) radicals into a singlet oligomer from B3LYP calculations. 


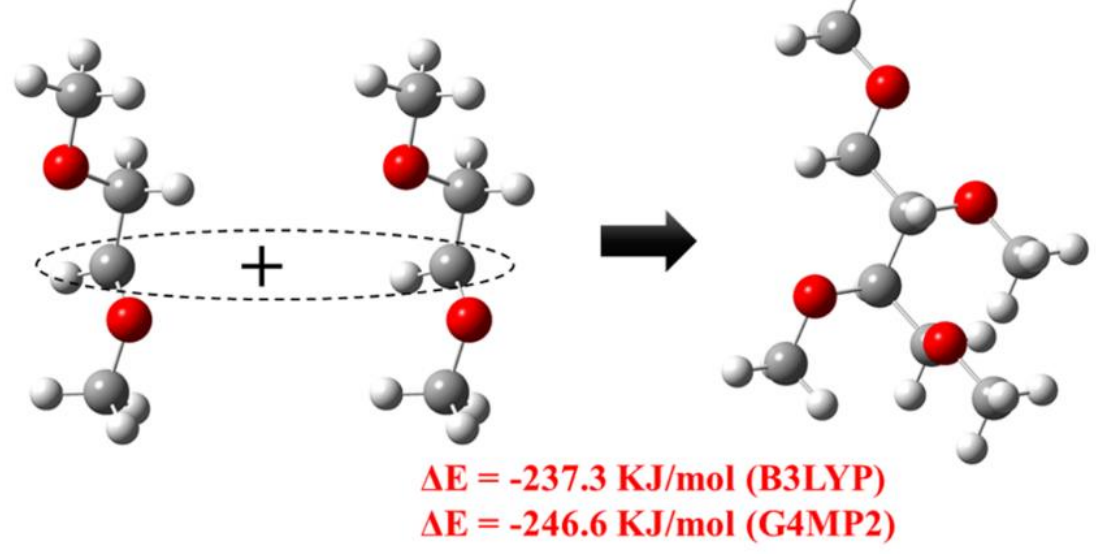

Figure S29D. Polymerization of two DME(-H) radicals into a singlet oligomer from B3LYP and G4MP2 calculations. 

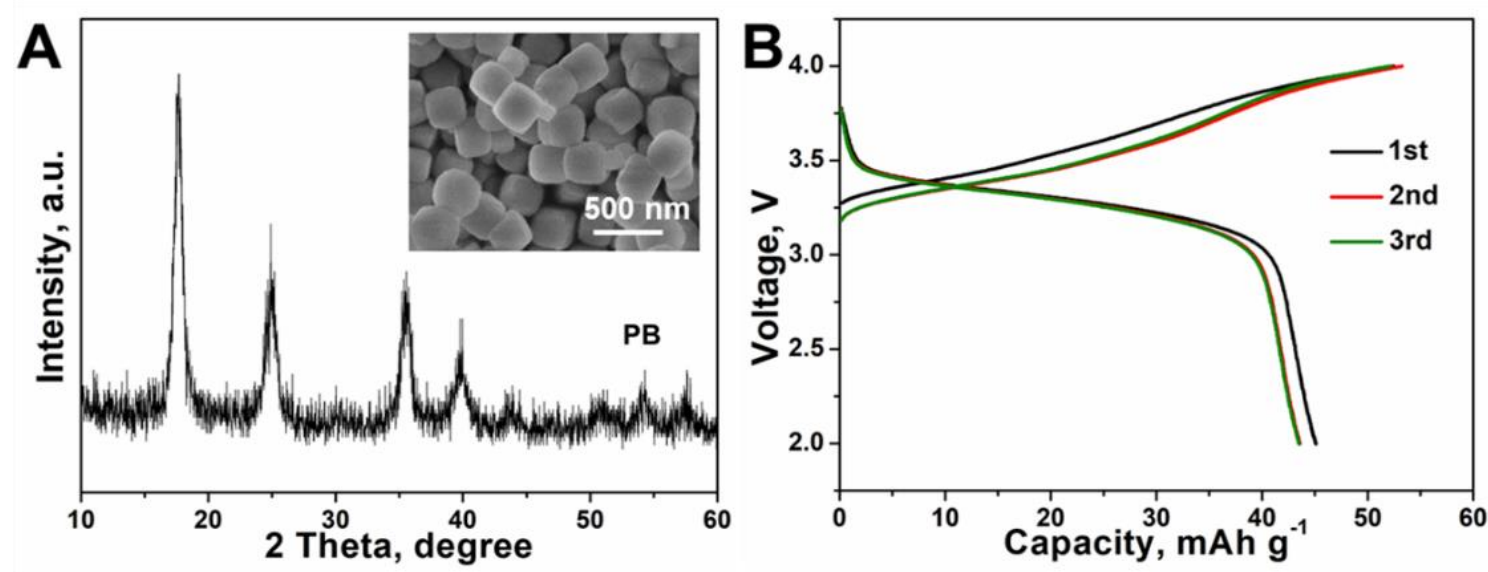

Figure S30. XRD pattern and SEM image (inset) of the Prussian blue $\left(\mathrm{K}_{0.72} \mathrm{Fe}\left[\mathrm{Fe}(\mathrm{CN})_{6}\right], \mathrm{PB}\right)$

(A). Charge/discharge profiles of $\mathrm{PB}$ in $1 \mathrm{M} \mathrm{KPF}_{6}$ in DME as electrolyte within the voltage range of $2-4 \mathrm{~V}$ at $0.2 \mathrm{~A} \mathrm{~g}^{-1}(\mathrm{~B})$.

Synthesis of Prussian blue Materials: Prussian blue $\left(\mathrm{PB}, \mathrm{K}_{0.22} \mathrm{Fe}[\mathrm{Fe}(\mathrm{CN}) 6]\right)$ was synthesized as reported by Lei et al. ${ }^{\mathrm{S} 10} \mathrm{In}$ a typical synthesis process, $0.4224 \mathrm{~g}$ of $\mathrm{K}_{4} \mathrm{Fe}(\mathrm{CN})_{6} \bullet 3 \mathrm{H}_{2} \mathrm{O}$ and $0.3244 \mathrm{~g}$ of $\mathrm{FeCl}_{3}$ were separately dissolved in 100 and $50 \mathrm{~mL}$ of deionized water. Then, the $\mathrm{FeCl}_{3}$ solution was dropwise added into the $\mathrm{K}_{4} \mathrm{Fe}(\mathrm{CN})_{6}$ solution with continuous stirring for 2 h. Subsequently, the mixture was aged for $24 \mathrm{~h}$ at room temperature and then the blue precipitates were collected via centrifugation and washed with deionized water and ethanol for several times respectively and dried in vacuum oven at $80{ }^{\circ} \mathrm{C}$. Finally, $\mathrm{K}_{0.72} \mathrm{Fe}\left[\mathrm{Fe}(\mathrm{CN})_{6}\right.$ was electrochemically obtained by discharging $\mathrm{K}_{0.22} \mathrm{Fe}\left[\mathrm{Fe}(\mathrm{CN})_{6}\right.$ to $2.0 \mathrm{~V}$ in a half cell.

Fabrication process of full cell: For making $\mathrm{K}_{0.72} \mathrm{Fe}[\mathrm{Fe}(\mathrm{CN}) 6$ electrode, a slurry was first prepared by dispersing $\mathrm{K}_{0.22} \mathrm{Fe}\left[\mathrm{Fe}(\mathrm{CN})_{6}\right]$ precursor, PVDF and carbon black in N-methyl2pyrrolidone solvent with a weight ratio of 90:5:5. Then the slurry was coated on Al foil and dried at $60{ }^{\circ} \mathrm{C}$ for $24 \mathrm{~h}$. Subsequently, a half KIB was assembled with $\mathrm{KPF}_{6}$ in DME as electrolyte, $\mathrm{K}$ as counter electrode and the above coated $\mathrm{K}_{0.22} \mathrm{Fe}\left[\mathrm{Fe}(\mathrm{CN})_{6}\right]$ as working electrode. The half cell was finally disachrged to $2 \mathrm{~V}$ to obtain $\mathrm{K}_{0.72} \mathrm{Fe}[\mathrm{Fe}(\mathrm{CN}) 6]$. 
For a full KIB, it was assembled with CoSe@NCNTs as anode, KPF6 in DME as electrolyte and $\mathrm{K}_{0.72} \mathrm{Fe}\left[\mathrm{Fe}(\mathrm{CN})_{6}\right](\mathrm{PB})$ as cathode; the anode and cathode ratio is kept at 1.0:1.2 (CoSe@NCNTs:PB). The mass loading of the active materials on CoSe@NCNTs anode is $1.2 \mathrm{mg} \mathrm{cm}^{-2}$. According to the initial cycle charge capacities, $360 \mathrm{mAh} \mathrm{g}^{-1}$ for CoSe@NCNTs and $\sim 45 \mathrm{~mA} \mathrm{~h} \mathrm{~g}^{-1}$ for $\mathrm{PB}$, the mass loading, $\mathrm{x}$, of the active materials on $\mathrm{PB}$ cathode is calculated by

$$
1.2 \times 1.2 \times 80 \% \times 360=45 \times x \times 90 \%
$$

yielding $\mathrm{x}=10.2 \mathrm{mg} \mathrm{cm}^{-2}$. 


\section{References}

(S1) Yu, Q.; Jiang, B.; Hu, J.; Lao, C. Y.; Gao, Y.; Li, P.; Liu, Z.; Suo, G.; He, D.; Wang, W. A.; Yin, G. Metallic Octahedral CoSe2 Threaded by N - Doped Carbon Nanotubes: A Flexible Framework for High - Performance Potassium - Ion Batteries. Adv. Sci. 2018, 5, 1800782.

(S2) Gao, H.; Zhou, T.; Zheng, Y.; Zhang, Q.; Liu, Y.; Chen, J.; Liu. H.; Guo, Z. CoS Quantum Dot Nanoclusters for High - Energy Potassium - Ion Batteries. Adv. Funct. Mater, 2017, $27,1702634$.

(S3) Zhao, Y.; Zhu, J.; Ong, S. J. H.; Yao, Q.; Shi, X.; Hou, K.; Xu, Z. J.; Guan, L. High - Rate and Ultralong Cycle - Life Potassium Ion Batteries Enabled by in Situ Engineering of Yolk-ShellFeS2@C Structure on Graphene Matrix.Adv.Energy Mater., 2018, 8, 1802565.

(S4) Wang, W.; Jiang, B.; Qian, C.; Lv, F.; Feng, J.; Zhou, J.; Wang, K.; Yang, C.; Yang, Y.; Guo, S. Pistachio - Shuck - Like $\mathrm{MoSe}_{2} / \mathrm{C}$ Core/Shell Nanostructures for High Performance Potassium - Ion Storage. Adv. Mater, 2018, 30, 1801812.

(S5) Li, L.; Zhang, W.; Wang, X.; Zhang, S.; Liu, Y.; Li, M.; Zhu, G.; Zheng, Y.; Zhang, Q.; Zhou, T.; Pang, W. K.; Luo, W.; Guo, Z.; Yang, J. Hollow-Carbon-Templated FewLayered $\mathrm{V}_{5} \mathrm{~S}_{8}$ Nanosheets Enabling Ultrafast Potassium Storage and Long-Term Cycling. ACS Nano, 2019, 13, 7939-7948.

(S6) Yang, C.; Feng, J.; Lv, F.; Zhou, J.; Lin, C.; Wang, K.; Zhang, Y.; Yang, Y.; Wang, W.; Li, J. Metallic Graphene - Like VSe2 Ultrathin Nanosheets: Superior Potassium - Ion Storage and Their Working Mechanism. Adv. Mater. 2018, 30, 1800036.

(S7) Fang, L.; Xu, J.; Sun, S.; Lin, B.; Guo, Q.; Luo, D.; Xia, H. Few - Layered Tin Sulfide Nanosheets Supported on Reduced Graphene Oxide as a High - Performance Anode for 
Potassium - Ion Batteries. Small 2019, 15, 1804806.

(S8) Zhang, R.; Bao, J.; Pan, Y.; Sun, C.-F. Highly Reversible Potassium-Ion Intercalation in Tungsten Disulfide. Chem. Sci. 2019, 10, 2604-2612.

(S9) Lin, H.; Li, M.; Yang, X.; Yu, D.; Zeng, Y.; Wang, C.; Chen, G.; Du, F. Nanosheets Assembled CuSe Crystal Pillar as a Stable and High - Power Anode for Sodium - Ion and Potassium - Ion Batteries. Adv. Energy Mater., 2019, 9, 1900323.

(S10) Lei, K.; Wang, C.; Liu, L.; Luo, Y.; Mu, C.; Li, F.; Chen, J. A Porous Network of Bismuth Used as the Anode Material for High - Energy - Density Potassium - Ion Batteries. Angew. Chem. Int. Edit., 2018, 57, 4687-4691. 